\title{
ANÁLISIS COSTO-BENEFICIO DE LAS POLÍTICAS MEDIOAMBIENTALES EN PAÍSES EN DESARROLLO*
}

\section{Michael A. Livermore}

En los últimos años, el análisis costo-beneficio ha comenzado a ser utilizado por aquellos países en vías de desarrollo que han requerido contar con mejores instrumentos para la elaboración de políticas y normativas ambientales de mayor complejidad. A partir de una descripción de los inicios de esta metodología como instrumento de apoyo para la toma de decisiones en países desarrollados, se describen algunas de las ventajas que el análisis costo-beneficio podría tener en países en vías de desarrollo. Asimismo, se describen algunos de los desafíos que plantea su incorporación en un contexto distinto de aquel en que ha sido mayoritariamente aplicado. A su vez, se analiza la especial importancia del análisis de cuestiones de distribución en países en vías de desarrollo. Por último, se presentan posibles reformas que pueden facilitar la adaptación de esta metodología a las necesidades y prioridades de países en vías de desarrollo.

Palabras clave: análisis costo-beneficio; políticas y normativas ambientales; países en desarrollo; economía del medio ambiente.

Michael A. Livermore. Abogado, New York University (NYU) School of Law. Director Ejecutivo del Institute for Policy Integrity.

* Este trabajo amplía el contenido de la presentación realizada en el seminario "Desafíos del análisis costo-beneficio ambiental", que se llevó a efecto en el Centro de Estudios Públicos (CEP) en Santiago de Chile el 17 de junio de 2009. Mis agradecimientos a los participantes en el seminario del CEP por sus comentarios y retroalimentación. Gracias también a David Mehretu, a Gonzalo Moyano y a Richard L. Revesz por sus oportunos comentarios.

Traducción al castellano de Loreto Serrano para Estudios Públicos. 


\section{Introducción}

\section{A}

unque a futuro, tal como están las cosas, van a predominar estándares elevados de regulación ambiental a nivel doméstico, algunos países están más avanzados que otros en esta materia. Las principales leyes ambientales de los Estados Unidos fueron promulgadas hace casi cuarenta años, mientras en algunos países menos desarrollados ni siquiera se han regulado los riesgos ambientales más serios. Sin embargo, en toda la miríada de las concepciones del bien existe un deseo casi universal de reducir los riegos para la salud y la seguridad, de respirar aire limpio y beber agua limpia. A medida que las economías de las naciones progresan, se advierte claramente una tendencia a ejercer un mayor control de los impactos negativos del desarrollo industrial, para asegurar que el crecimiento económico no se genere a costa de un entorno inhabitable.

La decisión de controlar la contaminación del medio ambiente es sólo el primer paso de un largo proceso para enfrentar la incertidumbre y arribar a soluciones de compromiso (making trade-offs) entre medio ambiente, salud pública y riesgo económico. Los países que tienen avanzados sistemas regulatorios utilizan el "análisis costo-beneficio" como una de sus principales herramientas para informar sus decisiones. El análisis costo-beneficio es una técnica que reúne, respecto a una decisión regulatoria, toda la información relevante que puede obtenerse, con el fin de identificar la alternativa que proporcione los mayores beneficios netos, considerados todos los factores. Mientras el análisis costo-beneficio se encuentra lejos de ser una ciencia exacta, dicho análisis ha crecido de manera exponencial en las últimas décadas a medida que se ha hecho evidente la necesidad de contar con una herramienta sistemática que permita incorporar los diversos factores que afectan las decisiones regulatorias en un modelo único y accesible.

El uso del análisis costo-beneficio en el proceso de toma de decisiones sobre el medio ambiente se ha propagado en los últimos años debido a que muchos países que aún se encuentran en tempranas etapas de desarrollo — y que ahora están comenzando a introducir regulaciones ambientales - quieren saber cómo esta herramienta podría informar sus decisiones. No obstante, pese a que el análisis costobeneficio se inició y se expandió en los países desarrollados hasta convertirse en una herramienta sumamente útil para ellos, va a requerir 
de importantes modificaciones para que pueda tener la misma utilidad en los países en desarrollo. Hay desafíos prácticos que se deben superar y también tendrían que introducirse cambios más de fondo para atender las necesidades de los países en desarrollo. Respecto a los primeros, los países deben sortear escollos políticos — tal como la necesidad de construir una base de apoyo para el análisis costo-beneficio y establecer, al mismo tiempo, sistemas regulatorios desde la base- y también deben resolver el problema de ser capaces de desarrollar los recursos analíticos necesarios para evaluar políticas ambientales complejas. Fundamentalmente, los efectos distributivos de la regulación deben ser un elemento central del análisis de los impactos regulatorios en el contexto de países en vías de desarrollo - tanto con respecto a la consideración actual de principios de equidad, como para asegurar que las futuras generaciones no sean afectadas inadecuadamente. Ulteriores modificaciones al análisis costo-beneficio, incluidas las iniciativas para incorporar reflexiones provenientes del análisis económico del proceso de desarrollo, también podrían ser necesarias.

Este trabajo está organizado de la siguiente manera. La primera sección proporciona breves antecedentes sobre el análisis costo-beneficio; examina su adopción y uso en el mundo desarrollado, y también las ventajas especiales que este análisis puede tener en los países en desarrollo. En la segunda sección se presentan los desafíos prácticos que enfrentarán muchos países en desarrollo a medida que intenten promover el uso del análisis costo-beneficio en el proceso de toma de decisiones de gobierno. En la tercera sección se discute la especial importancia para los países en desarrollo del análisis de la distribución de los costos y beneficios. La cuarta sección se centra en las reformas que podrían ayudar a que el análisis costo-beneficio se adapte mejor a las necesidades y prioridades de los países en desarrollo.

\section{Antecedentes: sistemas actuales y sus potenciales particulares}

El análisis costo-beneficio se ha convertido en una herramienta ampliamente usada para mejorar el proceso de toma de decisiones a lo largo del mundo desarrollado. Asimismo, también tiene un potencial especial en los países en desarrollo para agregar calidad, transparencia y eficiencia a las regulaciones concernientes al medio ambiente, salud 
pública y salud ocupacional. Si bien hay diferencias claras e importantes entre las economías desarrolladas y las economías en desarrollo para efectos de introducir regulaciones, muchas de esas disimilitudes proporcionan una justificación adicional para usar el análisis costobeneficio en los países en desarrollo.

\section{A. Análisis costo-beneficio en economías desarrolladas}

El análisis costo-beneficio de las políticas ambientales se ha convertido en una práctica común en la mayoría de los países desarrollados. Según expresara Cass Sustein (jefe de la oficina encargada de supervisar los análisis costo-beneficio en las agencias federales de los Estados Unidos), el propósito del análisis costo-beneficio es institucionalizar la práctica de "piensa antes de actuar" con respecto a las políticas del medio ambiente, de salud pública y de salud ocupacional ${ }^{1}$. El análisis costo-beneficio hace una estimación de las consecuencias positivas y negativas de las políticas y luego las compara con un parámetro común para identificar los efectos netos de la regulación. Según la formulación normal de los criterios costo-beneficio, el propósito de la regulación es maximizar los beneficios netos en el margen: esto es, para adoptar una regulación se llega hasta el punto donde el beneficio marginal sea igual a los costos marginales².

Los Estados Unidos han puesto el análisis costo-beneficio en el corazón de su sistema regulatorio. En 1981, el Presidente Ronald Reagan firmó la Orden Ejecutiva 12.291 que dispuso que todas las agencias ejecutivas debían realizar análisis costo-beneficio antes de adoptar una nueva regulación. La orden también confería autoridad a la Oficina de Información y Asuntos Regulatorios (Office of Information and Regulatory Affairs, OIRA), dependiente de la Oficina de Administración y Presupuesto (Office of Management and Budget, OMB) de la Casa

${ }^{1}$ Declaraciones de Cass Sustein en audiencia pública para considerar su nominación al cargo de Administrador de la Oficina de Información y de Asuntos Regulatorios (Office of Information and Regulatory Affairs), de la Oficina de Administración y Presupuesto (Office of Management and Budget) (Videocast in 42:11). Véase http:// hsgac.senate.gov/publicindex.cfm?FuseAction=Hearings.Hearing\&Hearing_ID=bd4574c99ca1-4f5c-9f0e-3618ee203a20.

${ }^{2}$ Esta formulación se deriva del supuesto de costos marginales crecientes y beneficios marginales decrecientes: el punto donde los costos marginales son iguales a los beneficios marginales representa el nivel óptimo de regulación, donde se maximizan los beneficios netos. 
Blanca, para revisar todas las regulaciones propuestas, con el fin de asegurar que se cumplieran las disposiciones de la mencionada Orden Ejecutiva. Solamente las regulaciones que aprobaran el test de costobeneficio serían aceptadas por la OIRA, salvo en los casos en que la ley le prohíba a una agencia aplicar el análisis costo-beneficio. Pero estas excepciones son muy limitadas; si bien hay algunos casos importantes en que la legislación explícitamente prohíbe el uso del análisis costobeneficio, en general los tribunales han protegido la facultad de las agencias de usar análisis costo-beneficio para estructurar el proceso de toma de decisiones en materia de regulaciones ${ }^{3}$.

La decisión del Presidente Reagan fue muy criticada, en especial por parte de grupos de interés que tienden a favorecer las regulaciones, como las organizaciones ambientalistas, grupos de consumidores y sindicatos. Sin embargo, aunque hubo debate sobre la nueva centralización de la autoridad de las agencias federales, y en especial por el uso del análisis costo-beneficio para evaluar políticas ambientales y de salud pública, durante toda la era Reagan siguió la práctica de someter las políticas a revisión de la OIRA y al análisis costo-beneficio. Este procedimiento se mantuvo durante los cuatro años de la presidencia de George H. W. Bush. Cabe destacar que cuando el Congreso tuvo la intención de dejar de financiar a la OIRA y se rehusó a confirmar a la persona nombrada por el Presidente George H. W. Bush para dirigirla, la supervisión de las regulaciones sencillamente pasó a una oficina menos formal, el Consejo de Competitividad (Council on Competitiveness), encabezado por el Vicepresidente Dan Quayle ${ }^{4}$.

El Presidente William J. Clinton continuó durante su mandato con la práctica de someter las regulaciones y las políticas ambientales y de salud pública a revisión y análisis de costo-beneficio. Cuando asumió la presidencia, dictó la Orden Ejecutiva 12.866, que actualizaba la Orden Ejecutiva de Reagan en varios aspectos importantes, pero man-

${ }^{3}$ Véase, por ejemplo, Entergy Corporation v. Riverkeeper, Inc., 129 S.Ct. 1498 (2008), donde se falló que la Agencia para la Protección del Medio Ambiente (EPA, por sus siglas en inglés) puede realizar análisis costo-beneficio para aplicar tecnología basada en los estándares estipulados en la Ley de Agua Limpia (Clean Water Act).

${ }^{4}$ Véase el artículo de Bob Woodward y David Broder: “Quayle’s Quest: Curb Rules, Leave 'No Fingerprints”, Wash. Post (enero 9, 1992), A1. También véase el artículo de Susan Reed, "Enemies of the Earth”, People Magazine (abril 1992), donde se informa que los grupos ecologistas veían al Consejo como "la puerta trasera a través de la cual han entrado las industrias para atenuar las regulaciones que les parecen demasiado costosas”, y De Witt (1993). 
teniendo la arquitectura fundamental de la "revisión centralizada" usando el análisis costo-beneficio. El gobierno federal ha operado desde entonces conforme a la Orden Ejecutiva 12.866, con sólo algunas modificaciones introducidas por el Presidente George W. Bush casi al final de su mandato, las que fueron anuladas por el Presidente Barack Obama cuando asumió la presidencia.

La Unión Europea (UE) también le ha dado un lugar importante al análisis costo-beneficio, en alguna de sus versiones, en los procesos regulatorios $^{5}$. La ampliación de la autoridad de las instituciones regulatorias a nivel europeo les ha conferido mayor poder a los organismos normativos de la Unión Europea, lo cual hace necesario que la discrecionalidad de estos organismos quede acotada y que sus decisiones se fundamenten en criterios transparentes y de común aceptación. La más clara muestra de la propagación del análisis costo-beneficio en la UE es la iniciativa "Mejor Regulación” ("Better Regulation”) que la Comisión Europea ha estado implementando desde 2002. La Comisión ha declarado que el objetivo de la iniciativa es

Asegurar que el marco regulatorio ayude a estimular el emprendimiento y la innovación, que permita una competencia empresarial más efectiva y que aproveche al máximo el potencial del mercado interno. Al hacerlo, la agenda “Mejor Regulación” contribuye al crecimiento y a la creación de empleos y, al mismo tiempo, mantiene los elevados estándares sociales, medioambientales, de salud y de protección al consumidor ${ }^{6}$.

Un componente clave del programa de Mejor Regulación es la exigencia de un análisis de los efectos de la regulación para todas las "iniciativas propuestas por la Comisión que podrían tener un impacto significativo"7. El propósito de la "evaluación de impacto" es "analizar los beneficios y los costos, y tratar de manera equilibrada todos los impactos económicos, sociales y medioambientales importantes de una iniciativa”8. Esta evaluación de los impactos de las acciones de la

${ }^{5}$ Wiener (2006).

${ }^{6}$ Véase Communication from the Commission to the European Economic and Social Committee and the Committee of the Regions, Third Strategic Review of Better Regulation in the European Union, No 2, COM (2009) 15 Final (enero 28, 2009) [de ahora en adelante, Communication from the Commission].

${ }^{7}$ Ibídem, $\mathrm{N}^{\circ} 6$.

${ }^{8}$ Ibídem. 
Comisión -incluyendo tanto las iniciativas legislativas como las regulatorias - constituye un claro avance en la instauración del análisis costo-beneficio, en alguna de sus versiones, en el corazón del proceso de toma de decisiones regulatorias a nivel europeo.

Asimismo, la Comisión ha dado importantes pasos para formalizar y estandarizar la evaluación de los impactos. En 2005, la Comisión emitió las "Directrices para la Evaluación de Impactos", un extenso documento técnico destinado a estructurar el proceso de evaluación de impactos a nivel de la UE y también para servir de guía en los procesos de decisión al interior de los países miembros. Las directrices han sido actualizadas varias veces, y luego de un largo proceso de revisión pública se dictaron nuevas directrices en junio de $2009^{9}$. Las directrices instan a los analistas a "identificar los impactos (directos e indirectos) económicos, sociales y ambientales (de las iniciativas propuestas) y la manera en que ellos ocurren (causalidad)"10. Además, las directrices estipulan que, luego de identificar los impactos, éstos se deben evaluar "comparándolos con el estándar en términos cualitativos, cuantitativos y monetarios”11. Las directrices también recomiendan que "cuando no es posible cuantificar, se debe explicar por qué"12.

De igual importancia para el desarrollo del análisis costo-beneficio en el sistema europeo es el hecho de que la Comisión ha "establecido una función muy exigente y centralizada de control de calidad, para lo cual creó la Junta de Evaluación de Impacto (Impact Assessment Board, IAB), que es independiente de los departamentos que generan las políticas”13. La IAB está encargada de revisar todas las evaluaciones de impactos realizadas por la Comisión. En enero de 2009, mediante un comunicado dirigido a los otros poderes políticos de la UE, la Comisión informó que la IAB "ha mejorado la calidad de las políticas al requerir que se vuelvan a presentar las evaluaciones de impacto del 32\% de los casos en 2008”14. La IAB también ha puesto "mayor énfasis en la necesidad hacer una cuantificación más sistemática de los impactos”15.

${ }^{9}$ European Commission: Impact Assessment Guidelines No 92/2009 del 15 de enero de 2009.

${ }^{10}$ Véase ibídem.

${ }^{11}$ Ibídem, $\mathrm{N}^{\circ} 6$.

${ }^{12}$ Ibídem.

${ }^{13}$ Communication From the Commission, supra nota 6, $\mathrm{N}^{\circ} 6$.

${ }^{14}$ Ibídem.

${ }^{15}$ Ibídem. 
Hay varias razones que justifican el uso del análisis costo-beneficio, la principal es que ayuda a estructurar la forma en que la agencia ejercerá su discrecionalidad. En los Estados Unidos, las leyes ambientales, de salud pública y de salud ocupacional les otorgan a las agencias administrativas — que dependen del Presidente — amplio margen para realizar su cometido oficial. Algunas leyes les confieren a las agencias un ámbito extraordinario de autoridad y relativamente pocas directrices. Por ejemplo, la Ley de Salud y Seguridad Ocupacional de 1970 establece, para los lugares de trabajo, estándares "razonablemente necesarios o apropiados como para que el trabajo o el lugar de trabajo sean sanos y seguros” ${ }^{\prime 6}$. Por razones obvias, este lenguaje le otorga amplia discreción al ministro para establecer un programa regulatorio y para adoptar - o rehusarse a adoptar - eventuales regulaciones en una gran variedad de materias. Otras leyes proporcionan más indicaciones a las agencias. Por ejemplo, muchas de las leyes básicas sobre medio ambiente que son administradas por la Agencia de Protección Ambiental (Environmental Protection Agency, EPA) estipulan detalladamente cómo debe proceder la agencia para establecer una regulación —incluye obligaciones para la agencia y requisitos claros. Cuando una agencia se abstiene de actuar en una materia que es de su competencia o si sobrepasa los límites legales, los tribunales federales de los Estados Unidos no han dudado en intervenir y corregir la actuación de la agencia ${ }^{17}$. Sin embargo, aun en los casos en que el Congreso ha establecido por ley instrucciones más completas para las agencias, éstas todavía mantienen un amplio margen de discrecionalidad, en especial en cuestiones técnicas donde los tribunales son reacios a revocar las decisiones de un organismo experto ${ }^{18}$.

Debido a esta amplia discrecionalidad, las agencias y los comentaristas han buscado maneras para estructurar y acotar el proceso de toma de decisiones de las agencias. Al no haber lineamientos claros acerca de cómo las agencias deben ejercer su facultad discrecional, éstas reciben un cheque en blanco y pueden ejercer su poder de manera poco transparente, ineficiente o incluso arbitraria. Se requiere de un mecanismo para crear un equilibrio entre pautas razonables para tomar

\footnotetext{
${ }^{16}$ Véase 29 U.S.C. § 652(8).

${ }^{17}$ Véase Massachusetts v. EPA, 549 U.S. 497 (2007); Lead Industries Association v. EPA, 647 F.2d 1130 (1980).

${ }^{18}$ Véase Whitman v. American Trucking Associations, 531 U.S. 457 (2001).
} 
decisiones y el legítimo ejercicio de la autoridad política otorgada a las agencias.

Una preocupación similar por la discrecionalidad y la existencia de un "déficit democrático" se puede argumentar para justificar el uso del análisis costo-beneficio en las instituciones de la Unión Europea. Las instituciones de la UE son supranacionales y, por lo tanto, están fuera del ámbito de los Estados nación que constituyen sus miembros —algunos ven esto como una falta de "demos" que socava la legitimidad democrática de estas instituciones ${ }^{19}$. Además, el hecho de que el poder de toma de decisiones está disgregado entre las instituciones de la UE y los Estados miembros y que el foco a nivel de las instituciones de la UE sea cada vez más tecnocrático han puesto también en tela de juicio la base democrática de la autoridad de la UE ${ }^{20}$. El descontento popular y la falta de interés en la UE alimentan asimismo la preocupación por la legitimidad de las decisiones a nivel de la UE. Dado que en algún nivel faltan instituciones democráticas que sirvan de base para las decisiones de la UE, entonces el análisis costo-beneficio puede, potencialmente, ser una alternativa — en el fondo y la forma - para dar legitimidad a las decisiones de las instituciones de la UE.

El análisis costo-beneficio proporciona así una solución parcial a los problemas que surgen cuando la autoridad para tomar decisiones no está radicada en instituciones con una amplia y reconocida legitimidad democrática. Sin bien el propósito teórico del análisis costo-beneficio consiste en estructurar el proceso de toma de decisiones en torno al criterio de maximizar los beneficios netos — ya sea fortaleciendo o debilitando las propuestas de regulaciones-, el contexto político que ha dado pie a un uso más amplio del análisis costo-beneficio es, por lo general, de carácter antirregulatorio. Tal como ha escrito Jonathan Weiner:

En los Estados Unidos se introdujeron reformas regulatorias en los años 1970 y 1980, en parte para combatir la inflación y la

${ }^{19}$ Véase Jolly (2005) para una discusión de la naturaleza y la importancia del concepto de "demos" en el contexto de la integración europea. Weiler (1995) argumenta que la falta de "demos” de la Unión Europea no le impide a la Unión tener instituciones democráticas.

${ }^{20}$ Véase, en general, Grimm (1995) (carta magna), para un análisis del llamado a establecer una constitución para la Unión Europea. Rabkin (2000) argumenta que la UE tiene un déficit democrático porque sus políticas están sesgadas en dirección hacia una socialdemocracia. 
recesión. Europa estableció el programa de Mejor Regulación en los últimos cinco años para remediar la débil economía que ha estado creciendo últimamente cerca de $2 \%$ al año $[\ldots]^{21}$. Casi huelga decir que uno de los objetivos clave de la reforma regulatoria es reducir costos. En los años 1980, los Estados Unidos tenía un Grupo de Trabajo para Mitigar la Regulación (Task Force on Regulatory Relief), que más tarde se llamó Consejo de Competitividad; la UE tiene ahora un Consejo de Comisarios de Competitividad (Competitiveness Council of Commissioners). En el Reino Unido, la Dirección para una Mejor Regulación (Better Regulation Executive), antes se llamaba Unidad de Impacto de la Regulación (Regulatory Impact Unit), y en los años noventa era la Unidad de Desregulación (Deregulation Unit) ${ }^{22}$.

Las regulaciones imponen costos a la sociedad; el más típico es el que exige a los actores privados incurrir en gastos de cumplimiento. Los costos de las regulaciones son menos evidentes que el gasto público directo: en vez de impuestos directos, el ciudadano medio sólo experimenta, indirectamente, los costos de cumplimiento a través de precios de consumo más altos, menos oportunidades de empleo y un menor rendimiento del capital. Dado que estos costos son menos evidentes, no se les asigna el mismo peso que al gasto directo del gobierno.

Cuando la atención pública se centra en los riesgos ambientales, de salud pública y de salud ocupacional, los programas regulatorios reciben un fuerte respaldo. En una economía donde hay escasa regulación, los riesgos ambientales y de salud pública son evidentes y sobresalen: están directamente relacionados con la vida cotidiana de los individuos y se pueden comprender en términos relativamente concretos. Los esfuerzos del gobierno por hacerse cargo de estos riesgos se explican con facilidad y la experiencia con los inconvenientes de la regulación es relativamente escasa.

Sin embargo, cuando la atención pública se vuelca hacia asuntos económicos —inflación, crecimiento, creación de empleos—, entonces los funcionarios suelen buscar mecanismos para minimizar los costos de la regulación. Algunas tendencias macroeconómicas escapan al control directo del gobierno, en tanto otras son manipulables a través de medidas que imponen aflicciones económicas de corto plazo, tal como

${ }^{21}$ Weiner (2006), p. 455.

${ }^{22}$ Ibídem, p. 456. 
disminuir la cantidad de dinero. Tratar de producir un cambio macroeconómico —como aumentar las oportunidades de empleo o reducir la inflación— a través de reformas regulatorias relativamente indoloras, puede aparecer muy atractivo.

Reconociendo la dificultad política de eliminar programas populares, los gobiernos han buscado criterios objetivos que puedan justificar medidas desregulatorias, y el análisis costo-beneficio ha demostrado ser una herramienta útil en este sentido. Tanto para los intentos por "mitigar las regulaciones" durante la presidencia de Reagan en los Estados Unidos, como para la campaña en pos de una "Mejor Regulación” en Europa, el análisis costo-beneficio ha sido una herramienta importante para calibrar los costos de las regulaciones. En vez de intentar revertir —en aras de reducir los costos de cumplimientotodos los avances hechos en materias ambientales, de salud pública y de salud ocupacional, los gobiernos han tratado de idear un mecanismo para equilibrar la necesidad de estos programas con la necesidad de que la economía crezca.

\section{B. Ventajas del análisis costo-beneficio para los países en desarrollo}

Si bien el uso del análisis costo-beneficio es bastante común en los Estados Unidos y Europa, esta práctica está recién asentándose en el mundo en desarrollo. Hay una variedad de aspectos institucionales e incluso conceptuales que han dificultado su adopción más amplia, pero el interés por el tema está creciendo en la medida en que numerosos países han empezado a desarrollar regulaciones más sofisticadas en materias de medio ambiente, salud pública y salud ocupacional. Muchas de las mismas preguntas que surgieron en los Estados Unidos y Europa van a surgir en otros países en el futuro cercano: ¿cuánto de limpio es suficiente? ¿Qué costos estamos dispuestos a imponer para lograr proteger el medio ambiente? ¿Cómo podemos establecer regulaciones para lograr resultados óptimos a los costos más bajos?

Además, por varias razones, el análisis costo-beneficio puede ofrecer ventajas especiales a los países en desarrollo. Primero, y lo más obvio, los países en desarrollo tienen menos dinero para despilfarrar y, por lo tanto, es de especial importancia contar con mecanismos que aseguren que las regulaciones generen beneficios que justifiquen los costos. Los problemas económicos que en los Estados Unidos y 
Europa dieron el impulso para la adopción del análisis costo-beneficio, son pequeños en comparación con las enormes dificultades económicas que enfrentan muchos países en desarrollo. Por estas razones, hay menos capital social para gastos en general, y en particular para proteger el medio ambiente, la salud pública y la salud ocupacional. Dado que los recursos son más limitados en los países en desarrollo, es doblemente importante que las regulaciones puedan lograr mucho con el menor gasto posible.

Sin embargo, el análisis costo-beneficio puede ayudar, asimismo, a justificar los gastos de las regulaciones, incluso en casos en que un gobierno tenga serias re1stricciones presupuestarias, si demuestra cuáles regulaciones tienen beneficios sociales netos — donde los beneficios sean mayores que los costos. Mientras algunos países desarrollados pueden estar dispuestos a adoptar regulaciones que tienen costos netos con el fin de lograr otros objetivos sociales de equidad o para librarse del peso de responsabilidades morales (por ejemplo, en el contexto de la protección de especies en peligro de extinción), los países en desarrollo enfrentan más restricciones para adoptar medidas que tienen costos netos. Pero cuando la regulación genera beneficios netos y, a su vez, no hay problemas compensatorios como las preocupaciones de índole distributivas, las consideraciones económicas justifican las regulaciones, e incluso los países pobres deberían moverse en esa dirección. En aquellos casos en donde los beneficios exceden a los costos, los países ricos y los pobres están en condiciones de igualdad: no regular en esas circunstancias es una decisión onerosa.

En segundo lugar, el análisis costo-beneficio puede ayudar a mejorar los sistemas regulatorios que carecen de transparencia, o en los cuales hay demasiados intereses políticos especiales. Así como hay una constante preocupación en los países desarrollados por haberles delegado excesivo poder a las agencias, creándose un "déficit democrático" entre los reguladores y el público al que se supone deben servir, existen dudas similares en muchos países en desarrollo acerca de la manera en que el Estado ejerce su autoridad. Las normas de transparencia de las acciones del gobierno, de participación pública, de acceso a los medios de comunicación, de revisión judicial y de justificación son a veces nuevas, o bien pobremente comprendidas y aplicadas, o inexistentes. Las instituciones independientes que sirven de contrapeso en los países desarrollados, como los medios de comunicación, las instituciones académicas, las asociaciones de profesionales y otros actores de la sociedad civil, en los 
países en desarrollo a menudo son débiles o están más sometidas a controles del Estado, o simplemente no cuentan con la información necesaria para lograr que los funcionarios públicos rindan cuentas. Es más, las propias instituciones democráticas pueden ser débiles, los votantes pueden estar mal informados acerca de los tejemanejes cotidianos del gobierno y las fuerzas de oposición pueden no ser capaces de enfrentar a los partidos de gobierno. Si bien estos mismos tipos de problemas pueden afectar a los países desarrollados, ellos son aun peores en muchos países en desarrollo.

El análisis costo-beneficio mejora la transparencia al hacer explícito el proceso de toma de decisiones, exigiendo que quienes toman las decisiones den a conocer sus datos, sus supuestos y expectativas, y que los análisis sean sometidos al escrutinio y crítica de expertos. Si bien el público con frecuencia no está en condiciones de evaluar los análisis costo-beneficio realizados por funcionarios de gobierno, los académicos, los comentaristas políticos y los actores de la sociedad civil pueden revisar y criticar los análisis costo-beneficio, algo, simplemente, que no podría suceder si las decisiones se tomaran a puertas cerradas. De este modo, el análisis costo-beneficio puede incrementar la capacidad de las instituciones externas para someter a escrutinio las acciones gubernamentales. Aunque el análisis costo-beneficio claramente no resuelve todos los problemas de transparencia de la sociedad, el hecho de obligar a los actores gubernamentales a explicitar las opciones que han escogido y la información utilizada en la toma de decisiones, puede cumplir una función importantísima para la transparencia.

Una tercera ventaja importante es su capacidad para identificar y desacreditar los programas ineficientes. Las regulaciones antieconómicas - disposiciones que inhiben la innovación o el crecimiento económico y que contribuyen muy poco a la protección ambiental o salud pública - son una clara amenaza para el desarrollo. Sin embargo, sin una metodología sistemática para identificar tales regulaciones, éstas pueden permanecer vigentes por años e incluso décadas, ocasionando un daño económico innecesario. El análisis costo-beneficio puede ayudar a identificar las malas políticas — en la mayoría de los casos, ojalá, antes de que se adopten. Quizás aún más importante, proporciona un lenguaje neutro para condenar a los malos programas. Los límites metodológicos del análisis costo-beneficio establecen restricciones respecto a hasta dónde se lo puede legítimamente "estirar” para justificar 
programas antieconómicos que pudiesen contar con el apoyo de funcionarios políticos. Al crear un criterio universal aplicable a una amplia gama de programas, el análisis costo-beneficio puede indicar cuáles programas son particularmente ineficientes o están mal concebidos.

Por estas razones, entre otras cosas, el análisis costo-beneficio puede constituir un complemento útil para el proceso de toma de decisiones en el mundo en desarrollo. Tal como les ha ayudado a los países desarrollados a acotar la discrecionalidad de quienes deciden las políticas, al entregar criterios sustantivos y procedimientos formales para un buen proceso de toma de decisiones, el análisis costo-beneficio puede mejorar sustantivamente el proceso de toma de decisiones en los países en desarrollo. En aquellos países en donde existen desafíos especiales -incluida la necesidad de impulsar el crecimiento económico e instalar instituciones políticas estables que funcionen bien- el análisis-costo beneficio puede resultar una herramienta especialmente útil.

No obstante, si bien puede haber un potencial especial para el análisis costo-beneficio en los países en desarrollo, asimismo existen desafíos especiales. Las siguientes dos secciones tratan directamente ese asunto; primero al analizar las barreras técnicas y políticas para un uso más amplio del análisis costo-beneficio, y luego al examinar temas conceptuales más profundos que surgen respecto del análisis costobeneficio en los países en desarrollo, y cuáles serían sus posibles soluciones.

\section{Desafíos prácticos}

Mientras el análisis costo-beneficio se ha generalizado en el mundo desarrollado, no ha sido adoptado con igual amplitud en los países en desarrollo. Hay muchas explicaciones posibles para ello, incluyendo desafíos políticos, económicos y de capacidad específicos.

\section{A. La política}

En los países desarrollados el análisis costo-beneficio es una técnica asentada que tiende a aumentar la legitimidad de las decisiones políticas. La revisión de las regulaciones mediante el análisis costo- 
beneficio se ha usado por casi tres décadas en los Estados Unidos. En los círculos académicos y políticos, al igual que en el grueso de la población, se acepta la ciencia económica como una herramienta legítima para el análisis de las políticas. El uso de la economía para justificar una política tiene como resultado generar un mayor apoyo para las políticas.

Hay algunas voces en las economías desarrolladas que no apoyan el uso de la economía o del análisis costo-beneficio para evaluar las políticas, pero esos grupos representan una pequeña fracción de la opinión pública política. De hecho, esos grupos que prescinden del análisis costo-beneficio socavan su capacidad para promover eficazmente sus propuestas de política. El ejemplo más claro de esto se advierte en el ámbito de las regulaciones, donde algunos grupos no han participado en foros en los que se toman importantes decisiones de política $^{23}$. El resultado es un proceso desbalanceado, donde unos intereses tienen mayor representación que otros.

Incluso en los procesos políticos en los que el análisis costobeneficio no tiene un papel institucional formal — por ejemplo en el Congreso y en los medios de comunicación- el análisis económico tiene amplia aceptación política. Cuando algunos grupos rechazan el análisis costo-beneficio, el daño tiende a ser mayor para las causas que ellos apoyan que para el propio análisis costo-beneficio. Quienes se oponen a una política pueden ser muy efectivos cuando consiguen mostrar que los analistas económicos tampoco la apoyan ${ }^{24}$.

El análisis costo-beneficio puede no gozar de la misma legitimidad en ciertos países en desarrollo. Parte de la legitimidad del análisis costo-beneficio y de la economía en general en los países desarrollados es simplemente "legitimidad de los resultados" (output legitimacy): se considera que ha contribuido con éxito a una tendencia de largo plazo

${ }^{23}$ Véase la entrevista con Sally Katzen, ex Subdirectora de Administración, OMB en Wash. D.C. (Feb. 20, 2007), en Revesz y Livermore (2008).

${ }^{24}$ Un buen ejemplo es cómo los opositores a la regulación de la EPA para las emisiones de gases efecto invernadero sostuvieron que la OMB se oponía a la regulación propuesta basados en un memorándum interno de la oficina que estipulaba que habría serias consecuencias económicas a raíz de las normas propuestas. Sin embargo, según descubrió el reportero David Roberts, la OMB nunca hizo esa afirmación, sino que se trató de uno de los comentarios efectuados en una revisión interinstitucional. Véase http:// www.grist.org/article/2009-05-13-omb-epa-sba-endangerment. 
de crecimiento y aumento del consumo. Mientras las consecuencias del análisis económico parezcan ser positivas en general, la gente y la clase política estarán dispuestas a aceptar su uso, pese a cualquier desconfianza o malentendido que pudieran tener al respecto.

El análisis económico no tiene, por definición, el mismo historial en los países en desarrollo. En muchos países, el campo del análisis costo-beneficio es visto como una importación extranjera con escasa aplicabilidad al tipo de materias propias del desarrollo. Si bien no hay nada inherente al análisis costo-beneficio que respalde un enfoque pro libre mercado para el proceso regulatorio, se podría hacer una estrecha relación, al menos a nivel sicológico, con el tipo de políticas conocidas como "Consenso de Washington", las que no cuentan con una aprobación universal en el mundo en desarrollo ${ }^{25}$. El análisis costo-beneficio va a gozar de menor legitimidad en la medida en que se le asocie con políticas o enfoques impopulares.

Además, los países desarrollados comenzaron a generalizar la aplicación del análisis costo-beneficio después de haber establecido importantes sistemas regulatorios para enfrentar riesgos ambientales, de salud pública y seguridad. El programa regulatorio inicial se estableció sobre la base de los riesgos percibidos por el público, lo que generó el ambiente político propicio para crear nuevas agencias reguladoras con amplias facultades y justificó una mayor intervención de las agencias reguladoras públicas en el mercado. El análisis costo-beneficio apareció después, como una herramienta para agregarle racionalidad a los regímenes preexistentes, que continuaron ejerciendo su autoridad.

La dinámica política que hizo que se utilizara el análisis costobeneficio en los Estados Unidos y en la Unión Europea no existe en los países en desarrollo. Tanto los Estados Unidos como la Unión Europea adoptaron el análisis costo-beneficio y la revisión de las regulaciones cuando sus economías enfrentaron períodos de crecimiento débil dentro de una tendencia de largo plazo de creciente prosperidad. Ellos ya habían logrado altos niveles de desarrollo, habían emprendido la regulación de riesgos en una escala ambiciosa y habían enfrentado muchas

${ }^{25}$ En particular, en muchos de estos países ha habido descontento por las políticas neoliberales que promueven las instituciones internacionales, en especial por las políticas contractivas de ajuste estructural que promueve el Fondo Monetario Internacional. Por supuesto que el término ["Washington Consensus"] lo han usado distintas personas para referirse a diferentes cosas, no todas malas. Véase Williamson (2004). 
de las dificultades subyacentes que continúan afectando como una plaga a los países en desarrollo. El análisis costo-beneficio en los países desarrollados se instaló, en parte, por la sensación de que los gobiernos necesitaban recortar el gasto en un bien "de lujo", a saber: los altos niveles existentes de protección contra riesgos ambientales y de salud pública.

Los problemas económicos que proporcionaron la base política para la adopción del análisis costo-beneficio —incluyendo la inflación y el persistente desempleo - están a menudo presentes de manera exacerbada en los países en desarrollo y muchas veces aparecen acompañados de una multitud de otros desafíos económicos. Sin embargo, los países en desarrollo, que enfrentan vastas restricciones económicas, nunca han estado en condiciones de gastar en "lujos” como la protección ambiental. En países que están iniciando el ciclo pro regulaciones, el argumento político en favor del análisis costo-beneficio tendrá que cambiar. En particular, cuando el análisis costo-beneficio está estructurado y es percibido como un instrumento para controlar la regulación, podría llegar a ser políticamente impopular y potencialmente dañino si en forma indebida desacelera u obstaculiza los sistemas regulatorios que están en sus inicios. Más bien, el análisis costo-beneficio debe ser conceptualizado de manera explícita como un mecanismo para establecer la agenda —una herramienta neutra para ayudar a los nuevos reguladores a identificar los problemas que se deben abordar primero-, que permite comparar alternativas y lograr el máximo de beneficios netos mediante una adecuada calibración de las regulaciones, de modo que no sean indebidamente estrictas o demasiado blandas. Sólo si el análisis costo-beneficio tiene este papel proactivo se evitará retrasar el desarrollo de regulaciones que son necesarias y podrá ser visto como un elemento productivo en el proceso de toma de decisiones políticas.

Finalmente, el amplio apoyo político del que goza el análisis costo-beneficio en los países desarrollados se debe, en parte, simplemente al hecho de haberse utilizado allí por un tiempo más largo. Los países que tienen menos experiencia con la herramienta naturalmente enfrentan mayor incertidumbre, y en los primeros años de su aplicación el análisis costo-beneficio puede enfrentar mayor oposición debido al temor a potenciales problemas. En este sentido, la mejor manera en que el análisis costo-beneficio puede legitimarse es demostrar su utilidad. 


\section{B. El problema de la comparación internacional}

Una cuestión particular que puede socavar el apoyo popular al análisis costo-beneficio en los países en desarrollo es el problema de la desigualdad entre países. Dado que las preferencias de riesgo (risk preferences) tienden a estar estrechamente relacionadas con la riqueza, es dable esperar que los países ricos tengan mayor disposición a pagar más para reducir los riesgos ambientales, de salud pública y de salud ocupacional que los países que están en sus etapas más tempranas de desarrollo ${ }^{26}$. El análisis costo-beneficio tomaría en consideración estas preferencias y, en definitiva, justificaría niveles de regulaciones menos estrictas en los países en desarrollo.

Desde un punto de vista netamente económico, el que haya diferencias regionales de preferencias en riesgos no es sorprendente ni preocupante. Las correlaciones entre riqueza y voluntad de pagar para evitar riesgos están bien establecidas ${ }^{27}$. De hecho, los difusos sistemas de gobierno que vemos a nivel internacional, y también al interior de aquellas naciones en las que rige alguna versión de división federal del poder o de "subsidiariedad", se originan y justifican generalmente por diferencias en las preferencias ${ }^{28}$. Si los habitantes del estado de California y del estado de Mississippi tienen distintas preferencias en materia de protección ambiental local, esas preferencias serán reivindicadas en las respectivas leyes de cada estado. Dentro de la Unión Europea, los países mantienen importantes niveles de autonomía respecto a las opciones de regulación y principios de "subsidiariedad” — según los cuales las decisiones quedan radicadas en los organismos de jurisdicción más locales que puedan tomar decisiones eficientes-, lo cual quedó estipulado en los documentos fundantes de la Unión ${ }^{29}$. A nivel internacional,

${ }^{26}$ La investigación empírica sobre la disposición a pagar y el riesgo en los países en desarrollo tiende a apoyar esta intuición. Véase Soma et al. (2007), sobre variaciones en la disposición a pagar de acuerdo al nivel de ingresos. Véase también Hammitt y Zhou (2005).

${ }^{27}$ Véase Armantier y Treich (2003).

${ }^{28}$ Véase Buchanan (1995). A su vez, para una refutación del argumento de que establecer una regulación ambiental a nivel federal es una manera de evitar una indeseable competencia implacable que conduce a un deterioro social (race to the bottom), véase Revesz (1992). Para una referencia en el contexto europeo, véase Wils (1994). Wouter aboga por una ampliación del principio de subsidiariedad.

${ }^{29}$ El Tratado de Roma, que fue enmendado por la Single European Act (1986) y por el Tratado de Maastricht (1992), establece que las políticas comunitarias sobre medio ambiente no impedirán que los Estados miembros puedan establecer medidas de protección más estrictas. El Tratado de Maastricht también aprobó explícitamente el principio de subsidiariedad. 
las diferencias en las preferencias y cultura dan pie a enormes diferencias en las opciones de política, no sólo con respecto a las regulaciones sino también en otras áreas como la responsabilidad civil.

Sin embargo, el hecho de que haya distintas preferencias para el riesgo, en especial cuando esas preferencias están estrechamente asociadas a niveles de desarrollo, genera un problema de "comparación internacional”. Dicho de manera más clara —y expresado en términos del lenguaje o la moralidad que a veces se usa para evaluar el análisis costo-beneficio-: “ ¿Tiene más valor la vida de un estadounidense que la vida de un chileno?”.

Este debate está lejos de ser académico. Una consecuencia de las diferencias en las preferencias de riesgo es que se justificarán niveles más bajos de protección ambiental en los países en desarrollo por su disposición a gastar menos para "salvar una vida” que los países desarrollados. La compensación recíproca (trade-off) entre crecimiento económico y protección ambiental simplemente es diferente en aquellos países que tienen menores niveles de desarrollo económico. Para algunos, el resultado es injusto porque pone en desventaja a las poblaciones de los países en desarrollo al dejarlas expuestas a mayores niveles de riesgo. $\mathrm{Si}$, tal como algunos han sostenido ${ }^{30}$, algún grado de protección del medio ambiente es un derecho humano, entonces ningún país puede caer por debajo de ese nivel de referencia, independientemente de las preferencias de riesgo o del nivel de desarrollo económico.

La otra cara de este argumento está presente en los países desarrollados, donde los sindicatos y los trabajadores se quejan de que los estándares más bajos de protección ambiental en el mundo en desarrollo constituyen una ventaja injusta para ellos. Las regulaciones ambientales y de salud pública imponen costos al capital y crean incentivos para que las industrias se trasladen a los países con regulaciones menos estrictas. El traslado de las industrias acarrea consecuencias para sus comunidades locales y para el empleo. En los estados de la industria metalúrgica ("rust-bell" states) estadounidense, incluyendo Ohio, Pennsylvania y Michigan, muchas industrias han cerrado sus fábricas y han despedido a miles de trabajadores. A menudo el trabajo

${ }^{30}$ Véase McCallion y Sharma (2000), y Boyle (2007). 
manufacturero sindicado y bien pagado es reemplazado por empleos en servicios de salarios menores y no sindicados, si es que llegan a ser reemplazados. Las regulaciones estrictas, junto a otros factores, tales como los altos costos de la mano de obra, crean incentivos para que las empresas se instalen en países menos desarrollados. Los sindicatos y las localidades dañadas por la fuga de capitales culpan algunas veces a los países en desarrollo por tener regulaciones que son demasiado débiles o se lamentan de que haya competencia por atraer industrias mediante la reducción de exigencias ambientales (race to the bottom) ${ }^{31}$.

Otra peligrosa consecuencia política que surge de las diferencias en las preferencias de riesgo es que, desde un punto de vista puramente económico, se puede justificar la transferencia del riesgo desde los países desarrollados a los países en desarrollo. Esta situación fue discutida por el actual asesor económico del Presidente Obama, Lawrence Summers, cuando estaba en el Banco Mundial. En 1991, un memorándum firmado por Summers decía, entre otras cosas, que: "la lógica económica de usar como vertedero de residuos tóxicos a los países con salarios más bajos es impecable y tenemos que asumirlo"32.

La reacción al memo de Summers fue rápida y global. Sólo a modo de ejemplo, muy pronto después de enviar el memo, el entonces ministro del Medio Ambiente de Brasil, Jose Lutzenburger, le escribió a Summers: "Su razonamiento es perfectamente lógico, pero totalmente insano [...] Su opinión [constituye] un ejemplo concreto de la increíble alienación, pensamiento reduccionista, crueldad social e ignorancia arrogante de muchos 'economistas' convencionales con respecto a la naturaleza del mundo en que viven"33.

La reacción a las propuestas de Summers indican, sin embargo, exactamente el tipo de peligros políticos que enfrentan quienes quieren expandir el uso del análisis costo-beneficio. El análisis económico a veces puede presentar las opciones de política de una manera descarnada e implacable, clarificando las compensaciones recíprocas

${ }^{31} \mathrm{Si}$ es que existe esa competencia que conduce a un deterioro (race to the bottom), o si se puede considerar ineficiente desde una perspectiva económica, es un tema distinto. Véase Revesz y Livermore (2008).

32 Véase Jim Vallette, Larry Summers' War Against the Earth, Counter Punch, http://www.globalpolicy.org/component/content/article/212/45462.html (última visita, Sep. 28, 2009).

${ }^{33}$ La cita está tomada de Jose Lutzenburger; ha sido reproducida en numerosos sitios web que se oponen al trabajo del Banco Mundial. También se encuentra en Jensen (2004). 
(trade-offs) entre bienes que tienen una alta carga valórica como la protección al medio ambiente y la salud pública. El análisis costobeneficio probablemente destaque la realidad de las desigualdades de ingreso a nivel internacional como protecciones que en algunos países se justifican y no así en otros.

Las comparaciones internacionales pueden suscitar fuertes sentimientos. Pero resolver este problema no va a ser fácil. Existen tres soluciones posibles, todas las cuales tienen serios inconvenientes. La primera sería "purgar" ("launder") en los países en desarrollo aquellas preferencias de las personas en las que se atribuye demasiado poco valor al riesgo. Hay posibles justificaciones para excluir esas preferencias - los riesgos tal vez no sean bien comprendidos; la población podría estar expuesta a problemas para procesar la información, o a mecanismos heurísticos imperfectos, vis à vis poblaciones comparables en los países ricos. Es posible que las preferencias se vean influenciadas por situaciones, preocupantes normativamente, que pueden aumentar la tolerancia al riesgo, tales como el acostumbramiento a riesgos involuntarios asociados a la pobreza, el crimen o conflictos internos. Más controvertida sería la afirmación de que las preferencias que se desarrollan en condiciones de pobreza son siempre coercitivas $\mathrm{y}$, por lo tanto, se pueden ignorar.

El argumento en contra de purgar las preferencias es doble. Primero, si las preferencias que sirven de base para el análisis costobeneficio son manipuladas, no queda claro qué resultados podría mostrar el análisis costo-beneficio. En forma característica, un análisis costo-beneficio que arroja un resultado positivo indicaría que la gente valora más el beneficio que proporciona la regulación que los costos que la regulación impone. Si se purgan las preferencias, los analistas tendrían que distinguir en sus afirmaciones entre el "verdadero bienestar” y el bienestar que describe la satisfacción de las preferencias. Aun cuando hay filósofos que han intentado crear un fundamento para el análisis costo-beneficio sobre la base de criterios objetivos de bienes$\operatorname{tar}^{34}$, en países pluralistas donde hay muchas concepciones aceptables del bien es extremadamente difícil llegar a un acuerdo sobre el contenido de ese criterio objetivo.

En segundo término, purgar las preferencias crea una posibilidad real de que las regulaciones que "pasan la prueba” del análisis costo-

${ }^{34}$ Adler y Posner (2006). 
beneficio serán sin embargo perjudiciales para las personas, conforme a sus propias estimaciones. Por ejemplo, si se adopta una regulación sobre salud ocupacional que imponga costos marginales a cada unidad del trabajo, ello se traducirá en una disminución de la productividad y, en consecuencia, los sueldos serán menores. Si los trabajadores valoran menos el beneficio de la seguridad que la disminución de sus sueldos, el Estado no les habrá hecho ningún favor.

Por último, los defensores de la idea de purgar las preferencias rara vez discuten la posibilidad de aumentar la tolerancia al riesgo en los países ricos. Desde una perspectiva netamente económica, ajustar las preferencias hacia arriba en los países en desarrollo podría significar una transferencia global de riqueza regresiva, puesto que algunas de las ventajas comparativas de los países en desarrollo - disposición a asumir más riesgos ambientales y de salud pública - se perderían. Dados los actuales niveles de desigualdad, las transferencias de riqueza desde los países en desarrollo hacia los países ricos son claramente problemáticas desde el punto de vista normativo.

La segunda alternativa para manejar el problema de la comparación internacional sería tratar las diferencias internacionales en relación con las preferencias de riesgo de la misma manera en que éstas son tratadas para objetivos domésticos. Los países desarrollados no generan valoraciones de riesgos diferenciadas para distintas poblaciones —ellos usan un valor promedio para toda la población. El uso de un valor promedio evita problemas complicados de equidad y, mientras los costos de las regulaciones no estén centrados en los sectores de más bajos ingresos, se produce una leve redistribución hacia abajo, puesto que la gente pobre recibe un poco más de protección que la que estaría dispuesta a pagar, pero los costos de la regulación son pagados, en gran medida, por los sectores más ricos de la población

Hay varias razones por las que probablemente no tendría éxito la estrategia de definir un valor global promedio para las preferencias de riesgo. A nivel conceptual, se enfrentaría a los problemas que se señalan más adelante en el caso de un país en vías de desarrollo. Las enormes diferencias de riqueza, sumadas a la importante concentración demográfica de la riqueza y el ingreso, harían muy improbable que se pudiese sostener el supuesto base para usar un valor promedio en un contexto doméstico — que los costos de la regulación siguen la trayectoria de la riqueza. Esto significa que en algunos casos los países 
pobres se verían obligados a adoptar regulaciones que generan costos netos, porque aun cuando se usó un valor promedio, ese valor estaba basado en parte en preferencias de riesgo de los países ricos, que en realidad podrían no estar pagando por la regulación. Del mismo modo, los países ricos se verían impedidos de adoptar algunas regulaciones que tienen beneficios netos, dado que el valor promedio está basado en valoraciones de riesgo de países pobres que no están sujetos a los costos ni a los beneficios. Una restricción del valor promedio para la regulación doméstica resultaría, entonces, en pérdidas reales de bienestar por el hecho de mantener un valor único global de riesgo.

Incluso si hubiera un argumento convincente a nivel conceptual para establecer un estándar global único de valoración del riesgo, no podría sostenerse desde un punto de vista político. Se requeriría ceder soberanía en materia de regulación ambiental y de salud pública, algo que pocos países estarían dispuestos a aceptar en forma voluntaria. Si los países en desarrollo se vieran obligados a adoptar regulaciones demasiado estrictas, o los países desarrollados no pudieran adoptar medidas suficientemente estrictas, la regulación generaría un gran descontento entre la población local. Y, dadas las grandes diferencias de riqueza a escala mundial y la considerable aglutinación de población pobre por un lado y de población rica por otro lado, el valor promedio del riesgo va a situarse muy lejos de la valoración óptima de riesgo para muchos países. Aun si fuera solamente por razones prácticas, es extremadamente poco probable que se adopte un valor universal en el futuro cercano.

La última opción para tratar el problema de la comparación internacional es simplemente enfrentar los potenciales efectos políticos que pueden producirse a raíz de las diferentes valoraciones del riesgo y, quizás, hacer algunas concesiones limitadas con el fin de evitar las consecuencias de mayor complejidad. Hay varias concesiones de ese tipo que son posibles. Se podrían evitar algunas transferencias de riesgo directas hacia los países en desarrollo, como, por ejemplo, el traslado de desechos tóxicos. Donde los países ricos están ocasionando riesgos a través de fronteras, por ejemplo, en el contexto del cambio climático, se pueden establecer políticas usando las preferencias de riesgo de los países ricos, porque son ellos los que cargarán con los costos. Los países ricos que quieren que los países en desarrollo adop- 
ten regulaciones más estrictas con el fin de disminuir las diferencias en ventaja comparativas para atraer a la industria, pueden crear sistemas compensatorios, al menos mediante transferencias tecnológicas. Si bien ninguna de estas alternativas son en estricto rigor económicamente eficientes, impedirían que se produzca una reacción que podría terminar siendo aún más costosa.

Finalmente, las diferencias en la valoración del riesgo ponen de relieve el tremendo problema de la desigualdad en la distribución de la riqueza a nivel global. Si alguien en los Estados Unidos o en Europa se sorprende de que una persona de un país en desarrollo no esté dispuesta a pagar lo que le parece una insignificante suma de dinero para evitar riesgos importantes, eso debería golpear las conciencias y mostrar de manera elocuente la necesidad de tomar medias reales para disminuir la pobreza global. La mejor solución no es esconder el problema de la desigualdad purgando las preferencias o creando un valor promedio global artificial, sino, por el contrario, abordar la cuestión de la desigualdad derechamente.

\section{Capacidad analítica}

Incluso en los países donde el análisis costo-beneficio tiene amplio apoyo, encontrar los recursos para aplicarlo en forma generalizada será un reto. Los países desarrollados han destinado recursos significativos para llevar a efecto el análisis costo-beneficio. Debido a que en Estados Unidos se ha practicado el análisis costo-beneficio a gran escala a nivel federal durante las tres últimas décadas, este país cuenta con la capacidad más sofisticada en esta materia. A fin de analizar distintas posibles políticas, las agencias administrativas estadounidenses han contratado un gran número de funcionarios con experiencia en economía, en análisis de riesgo y en disciplinas relacionadas. Muchas agencias cuentan con oficinas que tienen la función de desarrollar agendas regulatorias. En particular, la Agencia para la Protección del Medio Ambiente (EPA, por su sigla en inglés) ha destinado tiempo, dinero y funcionarios para realizar análisis costo-beneficio. Entre otros pasos, la EPA creó el Centro Nacional para la Economía Medioambiental (National Center for Environmental Economics, NCEE), que emplea a docenas de economistas y a otros profesionales con el fin de que "realicen y supervisen investigación y desarrollo de métodos analíticos 
económicos”, “dirijan la [...] elaboración de informes económicos de la EPA”, "proporcionen orientación para la realización de análisis económicos", y "preparen sus propios métodos de análisis de las políticas medioambientales”35 . Además de la NCEE, la EPA creó el comité permanente del Consejo Asesor de Ciencias —el Comité Asesor en Economía del Medio Ambiente (Environmental Economics Advisory Committee, EEAC) - integrado por economistas y otros expertos del mundo académico, que orienta a la EPA en el análisis económico de las políticas del medio ambiente.

La EPA incluso ha desarrollado sus propias extensas directrices para realizar análisis económicos de las regulaciones medioambientales que se proponen ${ }^{36}$. Las directrices cubren temas como los supuestos apropiados respecto a la disposición a pagar para evitar riesgos, las tasas de descuento que se deben usar cuando los beneficios devengan en el futuro, cómo estimar mejor los costos que involucra el cumplimiento de las regulaciones propuestas, identificación de las alternativas de política adecuadas, y el alcance de las consecuencias secundarias que se deben considerar. Dichas directrices son un documento técnico extremadamente bien articulado que se basa en décadas de estudios e investigación en el campo de la economía del medio ambiente y del análisis costo-beneficio.

Además de la capacidad administrativa al interior de las agencias a nivel federal, también existen organismos centralizados: la Oficina de Información y de Asuntos Regulatorios (Office of Information and Regulatory Affairs, OIRA), ubicada dentro de la Oficina de Administración y Presupuesto (Office of Management and Budget, OMB), que está encargada de supervisar el análisis costo-beneficio que realizan todas las agencias. Esta oficina tiene, complementariamente, varias docenas de funcionarios profesionales que se han especializado en la ejecución de análisis costo-beneficio y revisión de regulaciones. En estas casi tres décadas de funcionamiento, la OIRA ha desarrollado una vasta capacidad para examinar las regulaciones y para mejorar la metodología y complejidad técnica de los análisis. Si bien esa capacidad tiene un costo — la OIRA puede ser relativamente lenta para cambiar o

${ }^{35}$ National Center for Environmental Economics (NCEE), acerca del NCEE, véase http://yosemite.epa.gov/ee/epa/eed.nsf/webpages/AboutNCEE.html (última visita, mayo 20, 2009).

${ }^{36}$ U.S. Environmental Protection Agency (EPA), Guidelines for Preparing Economic Analysis (2000). Disponible en http://yosemite.epa.gov/ee/epa/eed.nsf/webpages/Guidelines.html/\$file/Guidelines.pdf. 
adoptar enfoques más de punta-, representa un activo extremadamente importante que facilita la aplicación generalizada del análisis costobeneficio en los Estados Unidos.

Más allá del gasto público directo también hay un aporte del mundo académico que proporciona gran cantidad de información y análisis, que complementa los esfuerzos del gobierno ${ }^{37}$. Los distintos campos de estudio como el análisis de riesgo, el análisis costo-beneficio y la economía ambiental y de salud pública se han perfeccionado a lo largo del mundo desarrollado, con profesores en las principales instituciones de educación superior dedicados a enseñar a los futuros profesionales y a mejorar y ampliar el campo a través de los estudios académicos. Sólo en los Estados Unidos existen varios centros interdisciplinarios dedicados al análisis costo-beneficio aplicado a materias regulatorias, incluyendo el Centro para el Análisis de Riesgo (Center for Risk Analysis) de la Universidad de Harvard, el Centro de Análisis Costo-Beneficio (Benefit-Cost Analysis Center) de la Universidad de Washington y el Instituto para la Integridad de las Políticas (Institute for Policy Integrity, IPI) de la Facultad de Derecho de la Universidad de Nueva York.

Otro factor que facilita el uso del análisis costo-beneficio en los países desarrollados es la vasta literatura que se ha generado durante las últimas décadas y que conforma la base para gran parte del análisis contemporáneo. Cualquier análisis de costo-beneficio va a incluir gran cantidad de importantes parámetros que relacionan, por ejemplo, escenarios de exposición al riesgo con resultados, y resultados con preferencias, a fin de estimar los beneficios de la regulación, o que calculan las necesidades de cumplimiento y desarrollos tecnológicos para estimar costos. Se ha hecho muchísima investigación científica para estimar, por ejemplo, los diversos parámetros concernientes a los puntos finales (end points) de exposición al riesgo y salud, que fácilmente podría trasladarse a otros países —es dable pensar que la curva de respuestas para las dosis de cancerígenos sea igualmente válida en distintos países (dejando de lado la exposición a múltiples contaminantes, que no es algo que ni siquiera el más sofisticado análisis de costo-beneficio puede considerar). Sin embargo, también

${ }^{37}$ Véanse, por ejemplo, Viscusi (1978); Farrow et al. (2004). Otros investigadores tratan el contexto institucional del análisis costo-beneficio y cómo éste puede mejorar el proceso de toma de decisiones. Véase, por ejemplo, Morgenstern (1997). 
se ha realizado abundante investigación sobre cuestiones económicas $y$, en particular, sobre preferencias de las personas en relación con la exposición al riesgo. Estos estudios se han hecho de diferentes formas: desde estudios de "valoración contingente", donde los encuestados deben indicar sus preferencias respecto a su disposición a pagar para evitar un riesgo, hasta análisis del mercado laboral, que considera información pasada sobre los salarios y riesgos diferenciales de accidente para inferir estadísticamente el aumento en la remuneración que exigen los trabajadores para realizar trabajos más peligrosos.

Es discutible que esta investigación sea aplicable a distintas sociedades. Como primera cuestión, es bien sabido que las preferencias de riesgo cambian según el nivel de riqueza: mientras más rica es una persona, más dispuesta estará a pagar para evitar riesgos. Existen algunas estimaciones de parámetros para definir esta relación ${ }^{38}$, pero son controvertidas ${ }^{39}$. Sin embargo, no está claro que se puedan hacer estimaciones fiables sobre preferencias de riesgo en los países en vías de desarrollo simplemente descontando las estimaciones de la disposición-a-pagar de los países ricos para dar cuenta de distintos niveles de riqueza; posiblemente existen factores culturales, sociales, políticos y otros, que también podrían influir en las preferencias de riesgo. Utilizar valores descontados desde los países desarrollados no parece ser un método adecuado para generar parámetros que siempre tengan sentido en otros contextos. Para incluir información precisa en el análisis, es probable que los países en desarrollo tengan que realizar una cantidad importante de investigación nueva sobre algunos parámetros económicos clave.

Es comprensible que en el mundo desarrollado se destinen recursos para el análisis de las regulaciones. Incluso donde las regulaciones tienen un impacto relativamente bajo, medido en términos de porcentaje de la economía, sus efectos en términos absolutos son importantes, dado el tamaño general de esas economías. En los Estados Unidos, el umbral para someter las regulaciones nacionales a un completo análisis de costo-beneficio es de cien millones de dólares al año -las regulaciones que no alcanzan a tener impacto son sometidas a

${ }^{38}$ Robinson y Hammitt (2009) (informe preparado para el Banco Mundial). Disponible en http://regulatory-analysis.com/robinson-hammitt-air-pollution-africa.pdf.

${ }^{39}$ Ibídem, Nº 19. 
menos instancias de análisis ${ }^{40}$. Del mismo modo, las directrices de la Unión Europea restringen los análisis completos de impacto sólo a políticas "significativas" y recomienda menos análisis a las políticas que proporcionalmente tienen un efecto menor ${ }^{41}$. Sin embargo, con el umbral relativamente alto establecido en los Estados Unidos hay todavía muchas regulaciones que son sometidas al análisis costo-beneficio. Dado el monto del valor económico en juego, destinar una cantidad relativamente pequeña de recursos para llevar a cabo los análisis costobeneficio, es dinero bien gastado.

Incluso dentro de los países en desarrollo las unidades más pequeñas de gobierno, tales como los estados federales en los Estados Unidos, a veces tienen dificultades para obtener los recursos analíticos necesarios para la realización de análisis costo-beneficio. El Institute for Policy Integrity de la Escuela de Derecho de la Universidad de Nueva York está en plena implementación de un programa a gran escala para determinar cómo los estados pueden usar la revisión regulatoria y el análisis costo-beneficio para desarrollar regulaciones ambientales y de salud pública. Quizás, tal como era de esperar, nuestros hallazgos preliminares, que concuerdan con anteriores investigaciones sobre la materia ${ }^{42}$, indican que los estados por lo general no destinan recursos importantes al análisis costo-beneficio, y la revisión de las regulaciones, cuando se lleva a efecto, es a menudo mucho más superficial que la revisión a nivel federal y, a veces, mucho menos sofisticada. Pero para los estados que cuentan con recursos limitados es razonable no gastar demasiado en realizar estudios que sólo se traducirían en mejoras marginales en la eficiencia regulatoria. Debido a que las regulaciones de los estados afectan a economías más pequeñas, los efectos absolutos de sus regulaciones son menores, de modo que los retornos en la inversión en análisis son más reducidos.

Es dable esperar que los países en desarrollo enfrenten dilemas similares cuando decidan qué nivel de recursos destinar al análisis costo-beneficio. Para los países pequeños con economías más bien chicas, en general no sería eficiente someter las regulaciones a onerosos análisis costo-beneficio. Debido a que habrá relativamente pocas

${ }^{40}$ El umbral se ha mantenido igual desde la primera Orden Ejecutiva. Compárese la Orden Ejecutiva No 12.866 de septiembre 30, 1993 (58 Fed. Reg. 51,735) con la Orden Ejecutiva No12.291 de febrero 17, 1981 (46 Fed. Reg. 13,193).

${ }^{41}$ Comisión Europea, Communication from the Comission..., $\mathrm{N}^{\circ} 13$.

${ }^{42}$ Hahn (1998). 
iniciativas de política que tengan un importante impacto económico como para justificar largos y costosos análisis de costo-beneficio, los costos de puesta en marcha requeridos para desarrollar una capacidad adecuada para realizar este tipo de análisis serían demasiado elevados. Los países en estadios más bajos de desarrollo pueden no contar con una clase profesional suficientemente grande como para que los integrantes de la comunidad que tengan niveles altos de educación se dediquen a realizar análisis regulatorios en vez de servir en otros cargos importantes que deben ser llenados.

Si bien el asunto de la capacidad analítica es importante, no representará barreras infranqueables en todos los casos. Además, se pueden dar algunos pasos — como reunir recursos analíticos de distintos países o realizar análisis para políticas similares en varios paísespara evitar redundancias y permitir a los países en desarrollo aprovechar las ventajas de trabajar a escala; ventajas que han facilitado a los países desarrollados justificar la asignación de grandes cantidades de recursos para el análisis de costo-beneficio. Es más, a medida que crecen las economías de los países, el impacto real de las regulaciones es mayor, aumentando con ello la justificación para asignar recursos escasos al análisis costo-beneficio de políticas ambientales, de salud pública y de seguridad.

\section{El problema de la distribución}

Examinar la distribución de los costos y beneficios es un aspecto fundamental en el análisis del impacto de las regulaciones. Puede haber diferencias de distribución dentro de una misma generación, de modo que unos carguen con los costos y otros reciban los beneficios. Los efectos también pueden darse en diferentes generaciones, en cuyo caso los beneficios o los costos se reparten de manera desigual a través del tiempo. A continuación se exploran ambos efectos.

\section{A. Equidad intrageneracional}

La crítica más fundamental al análisis costo-beneficio, basada en la desigualdad de la distribución dentro de una misma generación, radica en que los insumos del análisis costo-beneficio son sensibles a la riqueza. La medida más importante de los beneficios de una regulación 
es la "disposición a pagar”. Si una regulación reduce el riesgo de exposición a un contaminante, esa reducción del riesgo se traduce a pesos. Para ello, se les pregunta a los beneficiarios de la regulación cuánto estarían dispuestos a pagar para evitar ese riesgo. Lo que la población afectada esté dispuesta a pagar para evitar el riesgo equivaldría al beneficio de la regulación propuesta.

La primera preocupación distributiva que presenta el análisis costo-beneficio estriba en que la disposición a pagar está estrechamente relacionada con la riqueza. Probablemente una persona con un mayor nivel de ingresos esté dispuesta a pagar más que una persona de ingresos más bajos por la disminución del mismo riesgo. Si el análisis costobeneficio individualizara la disposición a pagar, o si distinguiera clases de beneficiarios de una regulación por nivel de ingresos, tendría como resultado otorgar más protección a las personas más adineradas que a la gente pobre, debido a que las primeras están dispuestas a pagar más por la protección. Para muchos, este resultado podría entrar en conflicto con conceptos fundamentales de equidad e igualdad ante la ley.

Hay dos respuestas básicas para esta crítica, una conceptual y una práctica. A nivel conceptual, los defensores del análisis costobeneficio pueden argumentar que la disposición a pagar es en realidad un indicador de los efectos de una regulación en materia de bienestar. La pregunta que hace el análisis costo-beneficio es si las regulaciones estimulan el bienestar, no sólo si la disposición a pagar excede a los costos. Al tomar en consideración el valor marginal decreciente del consumo, el análisis costo-beneficio podría estructurarse, teóricamente, para identificar las consecuencias de una regulación en términos de bienestar, de modo de aprobar regulaciones que maximicen el bienestar neto ${ }^{43}$. Esta respuesta sirve de base para las técnicas de análisis costobeneficio que le otorgan mayor peso a las políticas que tienen beneficios netos para los individuos de ingresos más bajos, tal como se plantea a continuación.

La respuesta más práctica señala que el análisis costo-beneficio, tal como se lo realiza, usa valoraciones promedio y no valoraciones individuales de los costos y de los beneficios de una política. Así, se

${ }^{43}$ Una consecuencia interesante del análisis costo-beneficio, en esta línea, es que justificaría transferencias directas de riqueza, donde se les quitaría dinero a los ricos y se les entregaría a los pobres. Si el bienestar es importante, entonces hay que considerar que se introduce cierto grado de error cuando sólo se mira la disposición a pagar. Armantier y Treich (2003). 
establece un valor estadístico de la vida igual para toda la población de los Estados Unidos; no hay valores separados para las personas de ingresos altos y para las de ingresos bajos. Esta situación se produce por dos razones técnicas muy simples — sería más complejo intentar dividir a la población en subgrupos, asignarle un valor diferente al riesgo en cada grupo, y luego clasificar todos los impactos de la regulación según esos subgrupos-, como también por la obvia dificultad política que surgiría si los grupos fueran tratados de manera diferente. Esta solución práctica socava la crítica distributiva, y mientras el peso de la carga se distribuya uniformemente en la población (o se aglutine hacia arriba) de hecho va a producir una tendencia distributiva hacia abajo (progresiva).

Algo se ha avanzado para integrar el análisis de la distribución de los costos y beneficios en la evaluación de las regulaciones. El decreto presidencial que norma la revisión de las regulaciones en los Estados Unidos explícitamente solicita que se realice un análisis de la distribución ${ }^{44}$, y las directrices de la EPA ${ }^{45}$ y otros documentos guía ${ }^{46}$ proporcionan los mecanismos para evaluar los impactos de las propuestas de regulación en términos de distribución de costos y beneficios. Sin embargo, el tema está lejos de haber sido resuelto y el Presidente Obama ha llamado la atención específicamente sobre la necesidad de desarrollar mejores herramientas para evaluar y sopesar los temas distributivos $^{47}$.

Un segundo orden de críticas señala que incluso cuando se usan valores promedios, el análisis costo-beneficio no es sensible a la distribución de los costos y de los beneficios de la regulación. En su forma más básica, el análisis costo-beneficio sólo busca maximizar los beneficios netos en forma agregada y no se hace cargo de cómo se distribuyen los beneficios de la regulación. En consecuencia, un programa que aumente la riqueza de los ricos y genere una carga para los pobres se podría justificar mediante el análisis costo-beneficio en tanto el valor de los beneficios de la regulación fuese mayor que el valor de los costos.

${ }^{44}$ Executive Order $N^{0}$ 12.866. Véase Robinson y Hammitt (2009), informe preparado para el Banco Mundial, sección 1(b) (5).

${ }^{45}$ EPA: Guidelines for Preparing Economic Analysis (2000).

${ }^{46}$ Office of Management \& Budget (OMB), Circular A-4, Regulatory Analysis 14 (2003).

47 “Regulatory Review", memorándum dirigido a los jefes de departamento y agencias ejecutivas, 74 Fed. Reg. 5977 (enero 30, 2009), en el que se solicita recomendaciones sobre el tema al director de la OMB. 
Por esta razón, el análisis costo-beneficio es potencialmente insensible a un aspecto importante de la regulación: cómo se distribuyen los costos y beneficios. Si no tenemos algún mecanismo que permita considerar esa distribución, el análisis costo-beneficio entregará una evaluación incompleta de las políticas. Si las decisiones sólo se basan en el análisis costo-beneficio, existe un riesgo real de que se adopten malas políticas. Por consiguiente, el análisis costo-beneficio debe ser complementado con alguna forma de análisis distributivo, de manera que entregue un cuadro más completo de las consecuencias de las regulaciones del medio ambiente, de la salud pública y de la salud ocupacional.

Estos temas distributivos, si bien son importantes en las economías desarrolladas, lo son mucho más en los países en desarrollo. La desigualdad de ingresos es un problema mucho mayor en los países en desarrollo, situación que algunos comentaristas plantean que ha sido exacerbada por la expansión de la globalización ${ }^{48}$ — toda vez que el comercio internacional, la rápida expansión de la tecnología de las telecomunicaciones, y la inversión extranjera crean, todos ellos, oportunidades económicas, pero también tienden cada vez más a concentrar la riqueza en menos manos ${ }^{49}$.

Desde una perspectiva normativa, la desigualdad de ingreso es especialmente preocupante cuando hay sectores de la población que viven al límite o al borde del colapso, y su acceso a vivienda, salud, alimentos y educación es insuficiente. Aun cuando abundan las teorías de la justicia distributiva, hay argumentos convincentes que sostienen que la gente debe tener, al menos, acceso a los recursos necesarios para lograr algún nivel de autonomía y autogobierno ${ }^{50}$.

${ }^{48}$ Véase Narula (2008): “Algunos han comenzado a narrar el cuento de las Dos Indias, donde las desigualdades se polarizan aún más por el inexorable avance de la globalización, y donde los indios son ungidos en el Club de los Billonarios”. Ben S. Bernanke, Presidente del Directorio de la Reserva, señalaba: "Más allá de los efectos del cambio tecnológico, la variedad de fuerzas económicas, agrupadas bajo el epígrafe 'globalización’, también puede haber sido un factor en el aumento de la desigualdad, pese a que estas fuerzas han proporcionado un importante estímulo al crecimiento económico y han mejorado el nivel de vida en general". En "The Level and Distribution of Economic Well-Being”, discurso pronunciado en la Cámara de Comercio de Omaha (Greater Omaha Chamber of Commerce), Feb. 6, 2007: Disponible en http://www.federalreserve.gov/newsevents/speech/Bernanke20070206a.htm.

${ }^{49}$ Véase Faux et al. (2006), donde se refieren al aumento en la desigualdad de ingresos como una tendencia preocupante a raíz del NAFTA; véase también Polaski (2003), disponible en http://www.carnegieendowment.org/files/nafta1.pdf.

${ }^{50}$ Véase Dworkin (1981). 
La consecuencia de estas dos realidades distributivas: mayor desigualdad total y poblaciones que tienen un nivel de vida de subsistencia o cercano a ese nivel, complica el panorama a los países en desarrollo que quisieran adoptar el análisis costo-beneficio. Primero, puede haber ciertos tipos de regulación que son simplemente inadmisibles desde un punto de vista moral, cualquiera sea la relación costobeneficio. Por ejemplo, si la regulación gravara a un grupo de individuos que tienen un nivel de vida de subsistencia o cercano a ese nivel, de modo tal que sus niveles de riqueza cayeran bajo la línea de subsistencia, esa regulación sería potencialmente inmoral, aunque ella produjera un aumento total de la riqueza. Para que la regulación que se adopte goce de legitimidad debe haber instalados mecanismos de compensación para aquellos que podrían verse afectados negativamente, de modo de asegurarles que no experimentarán posibles consecuencias catastróficas en su bienestar, ni siquiera pequeños cambios negativos en términos de su riqueza.

Segundo, donde haya una marcada desigualdad se requiere especial atención para asegurarse de que esta situación no vaya a empeorar. Los economistas piensan, por lo general, que aumentar la equidad conlleva un costo en la productividad económica ${ }^{51}$, de tal modo que medidas que se adoptan para mitigar la pobreza suelen distorsionar los incentivos y reducen la productividad general de la economía. Las regulaciones que exacerban la desigualdad pueden ser consideradas, entonces, como políticas que imponen costos reales a sociedades que deben tomar medidas para reducir esa desigualdad en la distribución del ingreso — por ejemplo, ampliando la política redistributiva a través de los impuestos. Debido a que los países en desarrollo ya tienen serios problemas distributivos, es probable que en el caso de que una regulación los agrave, el gobierno tenga que tomar medidas para contrarrestar esos efectos. El análisis costo-beneficio debe tomar en cuenta estos costos, porque de lo contrario estaría pasando por alto una consecuencia clave de la regulación.

Tercero, el enfoque que se ha aplicado en los países desarrollados, en cuanto a usar una sola medida para toda la población con el propósito de valorar los beneficios de una regulación, permite obtener resultados razonables si se logra una distribución del peso de la regula-

${ }^{51}$ Los avances recientes en la economía del desarrollo cuestionan este punto de vista, tal como se discutirá más adelante. 
ción que se aproxime a la distribución de la riqueza — esto es, sobre la población más adinerada recae el mayor peso de la regulación. Si el peso de la regulación no está distribuido de esta manera, entonces habrá transferencias negativas de riqueza, o bien se habrá adoptado una regulación simplemente ineficiente. Por ejemplo, si tanto la carga como el beneficio de la regulación recaen sólo en el quintil más bajo, pero las valoraciones del riesgo están basadas en el quintil del medio, entonces la regulación será ineficientemente exigente. Del mismo modo, si el peso y los beneficios sólo recaen en el quintil más alto, la regulación será ineficientemente débil. Si el quintil más alto se beneficia y el más bajo recibe el peso, se producirá una transferencia de riqueza normativamente complicada.

Debido a que la desigualdad de ingresos es más aguda en los países en desarrollo, es posible que un mayor número de propuestas de regulación caigan en esta categoría problemática donde el uso de un valor promedio para el riesgo tendrá consecuencias nefastas. Si ese fuera el caso, entonces es necesario desarrollar un mecanismo alternativo para valorar el riesgo, que evite esas consecuencias y que, al mismo tiempo, respete el compromiso de equidad y de igual protección. Tal como están las cosas, no existe una metodología que se pueda considerar como una candidata obvia para hacer esa valoración.

Estas cuestiones distributivas constituyen un claro desafío para la expansión del uso del análisis costo-beneficio en los países en desarrollo. Específicamente, hacen necesario desarrollar formas más sutiles y sofisticadas de llevar a cabo el análisis distributivo y, a su vez, hacen necesario que ese estudio sea incorporado al análisis costo-beneficio para la evaluación de los impactos de las políticas propuestas en materia de medio ambiente, salud pública y de salud ocupacional. Aun cuando en el mundo desarrollado se han hecho algunos intentos para encarar las consecuencias distributivas de las regulaciones, éstos han sido rudimentarios y no son suficientes para la tarea que enfrentan los países en desarrollo para establecer políticas. Serán los dirigentes e intelectuales de los países en desarrollo quienes tendrán que crear la próxima generación de herramientas de análisis para abordar estas materias.

\section{B. Los desafíos del análisis distributivo}

Hay varios métodos mediante los cuales se podría incorporar el análisis distributivo al estudio del impacto de las regulaciones. La elec- 
ción de uno de estos métodos va a reflejar tanto necesidades analíticas como limitaciones, y también opciones valóricas sociales acerca de cómo debería determinarse la distribución de costos y beneficios en las políticas públicas concernientes al medio ambiente y la salud pública.

\section{Cálculo de la distribución}

En lo medular, el análisis de la distribución de costos y beneficios se basa en un ejercicio de cálculos: no sólo se deben calcular los costos y los beneficios totales, sino también se debe determinar qué grupos cargan con esos costos y cuáles reciben esos beneficios (hasta algún nivel predeterminado de detalle). Surgirán preguntas normativas incluso en esta primera etapa: el analista deberá identificar las características que son relevantes para el análisis. La distribución se puede medir por región, por nivel de ingresos, raza, género, edad, estatus socioeconómico, tamaño de la empresa, industria o cualquier otro posible conjunto de características que se definan como relevantes para los objetivos de la política. La decisión inicial sobre los grupos en los que se debe concentrar el análisis distributivo se convertirá en el cimiento de las decisiones futuras acerca de cómo sopesar las desigualdades en la asignación de los costos y los beneficios.

Segundo, se debe determinar el alcance del análisis de la distribución de costos y beneficios. Una política puede tener un amplio rango de efectos directos e indirectos y la tarea analítica sería potencialmente ilimitada si se deben estimar todos los efectos. En el análisis costo-beneficio estándar, la norma tradicional para tomar decisiones indica que se debe terminar el análisis cuando la información que genera la investigación adicional sobrepasa los costos (incluyendo la demora) de llevarla a cabo. El análisis de la distribución de costos y beneficios no admite una regla tan sencilla: se requiere de una decisión normativa acerca del valor de la información distributiva para determinar los recursos analíticos que deberían destinarse.

Posiblemente el análisis distributivo también requiera que se les dé mayor atención a ciertos tipos de efectos de una política. Hay una variedad de "caminos" mediante los cuales una política ambiental puede tener consecuencias distributivas regresivas: esto es, cuando los individuos de bajos ingresos cargan, proporcionalmente, con los mayores costos y reciben los menores beneficios de una política, como porcen- 
taje de la riqueza total ${ }^{52}$. Estos caminos incluyen los aumentos de precio de los productos, la disminución de los salarios reales, la asignación de nuevos derechos de propiedad, la valoración diferencial, los rendimientos crecientes de la propiedad de bienes inmuebles y los efectos de transición/empleo ${ }^{53}$.

Algunos de estos caminos se pueden incorporar con cierta facilidad en el análisis de impacto de las regulaciones. Por ejemplo, la creación de derechos de propiedad sobre la emisión de contaminantes y la asignación de estos derechos, digamos, mediante un sistema capand-trade - en el cual se fijan límites a las emisiones totales y los derechos de emisión se asignan entre los emisores actuales- tendrá claras consecuencias distributivas. Dado que el objetivo de la política es crear nuevos derechos, y dado que es probable que los medios de asignación de los nuevos derechos sean explícitos, resulta bastante sencillo anticipar las consecuencias distributivas de ese aspecto específico de una política.

Por otra parte, los efectos secundarios de la misma política — por ejemplo, un sistema de cap-and-trade para algunos contaminantes ambientales - son más difíciles de anticipar, y resulta especialmente difícil anticipar en quiénes recaerán las consecuencias de esos efectos secundarios. Es probable que un sistema de cap-and-trade genere un aumento del costo de los factores en ciertos procesos industriales, lo que podría ocasionar pérdidas de valor para los accionistas (efecto progresivo) y pérdidas de empleos (efecto regresivo). Otras industrias que producen bienes sustitutos, o que hacen un uso más eficiente de la regulación del factor, probablemente se beneficien con la política al aumentar el valor para los accionistas (efecto regresivo), pero también se podrían generar nuevos empleos (efecto progresivo). Los precios de consumo para necesidades básicas como la energía o los alimentos tal vez aumenten, con lo cual se produciría un efecto regresivo. Pero los precios de consumo para bienes de lujo también podrían aumentar, es decir, un efecto progresivo $^{54}$.

Hay otros dos factores que complican. Primero, siempre que ello sea factible, es probable que los beneficios de la regulación ambien-

${ }^{52}$ Véase Fullerton y Karney (2009).

${ }^{53}$ Ibídem.

${ }^{54}$ Pese a las dificultades para modelar los efectos de distribución del control de los gases de efecto-invernadero, hay diversos intentos sofisticados. Véase, por ejemplo, Burtraw et al.( 2009). 
tal sean incorporados a los precios de mercado, lo cual genera complicaciones, dado que los beneficios se distribuyen dentro del mercado. Por ejemplo, una regulación del uso del suelo que prohíba la construcción de nuevos edificios en el centro de la ciudad, probablemente va a generar un aumento en el valor de los edificios existentes. Algunos dueños de esos edificios van a vender a precio de mercado, generando un mayor precio para el nuevo comprador, y de esta manera conseguirán una ganancia caída del cielo. Por otra parte, si debido a ello aumentan los valores de los alquileres, los arrendatarios van a sufrir trastornos y posibles costos de transición, aunque nuevos arrendatarios, dispuestos a pagar mayores precios, disfrutarán de sus mayores excedentes de consumo. Un análisis costo-beneficio estándar podría aceptar precios mayores como un beneficio de la regulación —que simplemente refleja la creación de riqueza como una consecuencia de la política-, pero el análisis de la distribución de costos y beneficios requiere de una investigación mucho más profunda respecto de quién se beneficia y quién pierde a medida que los efectos de los aumentos de precios se propagan a través de la economía.

Segundo, el análisis distributivo podría requerir que se tomen en cuenta las diferentes valoraciones de los beneficios de una regulación, de una manera que no lo hace el análisis de costo-beneficio estándar. Tal como se planteó antes, las valoraciones individuales de los beneficios de una política ambiental pueden estar relacionadas con la riqueza —mientras mayor sea el ingreso de una persona, más alta será su valoración promedio de un beneficio ambiental dado. En consecuencia, hay un segundo mecanismo mediante el cual los beneficios pueden tener un efecto regresivo desde el punto de vista distributivo - incluso si cada uno de los ciudadanos recibe el mismo beneficio ambiental, las personas más adineradas obtendrán mayor satisfacción debido a que ellas valoran más esos beneficios.

2. Respuestas política-a-política versus respuestas holísticas a las inquietudes sobre distribución de costos y beneficios

Luego de reunir los hechos principales acerca de cómo se distribuyen los costos y beneficios, quienes formulan las políticas deben enfrentar la cuestión de cómo incluir en el proceso de toma de decisiones las preocupaciones distributivas. Cuando hay un gran número de 
políticas, los efectos distributivos de algunas de ellas se anulan por los efectos distributivos de otras. Algunos grupos que resultan beneficiados por una determinada regulación son gravados por otras regulaciones. De este modo, en una amplia gama de opciones de política, los desequilibrios distributivos tenderán a autocorregirse. Si la distribución se corrige a nivel de cada política individual, puede suceder que algunos de los efectos distributivos — que se anularían mediante el curso normal de la toma de decisiones - se eliminen a costa de la eficiencia general.

Un ejemplo es ilustrativo. Imagine dos políticas, Alpha y Beta, que imponen costos de 100 dólares y generan beneficios por 200 dólares. Alpha impone costos a la Persona B y genera beneficios a la Persona A, y Beta hace lo contrario. Existen políticas alternativas, Alpha' y Beta', cada una de las cuales impone costos de 55 dólares a cada persona y genera beneficios de 100 dólares para cada persona.

\begin{tabular}{|c|c|c|c|c|}
\hline & \multicolumn{2}{|c|}{ A } & \multicolumn{2}{|c|}{ B } \\
\hline & $\begin{array}{c}\text { Costos } \\
\$\end{array}$ & $\begin{array}{c}\text { Beneficios } \\
\$\end{array}$ & $\begin{array}{c}\text { Costos } \\
\$\end{array}$ & $\begin{array}{c}\text { Beneficios } \\
\$\end{array}$ \\
\hline Alpha & 0 & 200 & 100 & 0 \\
\hline Alpha' & 55 & 100 & 55 & 100 \\
\hline Beta & 100 & 0 & 0 & 200 \\
\hline Beta' & 55 & 100 & 55 & 100 \\
\hline
\end{tabular}

Si se realiza un análisis de la distribución de los costos y beneficios a nivel de cada política, entonces es posible que se elija Alpha' y Beta'. Bajo Alpha, la distribución de los costos y los beneficios es muy desigual, pues la Persona A logra trescientos dólares más que la Persona B. Bajo Alpha', los dos grupos reciben el mismo beneficio neto, y ninguno resulta más favorecido que el otro.

Del mismo modo, bajo Beta hay una distribución similarmente desigual de los costos y beneficios. Si se evalúa cada política por separado, entonces las políticas alternativas, que arrojan una distribución menos desigual, parecen más adecuadas.

No obstante, si se realiza un análisis de ambas políticas en conjunto, se escogería a Alpha y Beta, debido a que ahora no se 
produce un desequilibrio distributivo. Los beneficios netos de las políticas alternativas son de 180 dólares, en tanto los beneficios netos de Alpha y Beta son, cuando ambas políticas se consideran en conjunto, de doscientos dólares - la evaluación conjunta de estas dos políticas arroja, entonces, un beneficio neto de 20 dólares con ninguna consecuencia distributiva negativa.

En este ejemplo, si se evalúan las políticas por separado, tal vez se elegirán las políticas alternativas que tienen menores consecuencias distributivas, pero que también proporcionan menos beneficios. En ambas regulaciones, la elección de las políticas alternativas resulta en una disminución de los beneficios totales netos sin que se produzca ninguna redistribución positiva de los costos y beneficios de las políticas consideradas en conjunto. En este caso, hacer modificaciones para tomar en cuenta la distribución de costos y beneficios de las opciones de política individuales conduciría a resultados menos eficientes que si se consideraran los impactos distributivos de la política ambiental.

Si bien este ejemplo es claramente estilizado, tiene aplicabilidad en el mundo real. Para el diseño de políticas públicas, esperaríamos entonces que haya probables distribuciones probables de cómo se repartirían los costos y beneficios de una regulación. Se espera que las distribuciones para todos los grupos en todas las regulaciones sean equitativas: esto es, los costos y beneficios deberían seguir a la población de cada grupo, de modo que todos los individuos tengan las mismas recompensas esperadas. En algunas regulaciones individuales, algunos grupos van a resultar más beneficiados que otros. Sin embargo, si se considera el conjunto de una serie de políticas, veríamos que las recompensas reales (actual payoffs) se acercan a las recompensas esperadas, conduciendo a una distribución bastante equilibrada de los costos y beneficios.

Esta situación se ve acrecentada por la teoría económica que sugiere que redistribuir a través de la regulación resultará con toda probabilidad más costoso que redistribuir a través de un impuesto y un sistema de transferencia ${ }^{55}$. En el ejemplo mencionado más arriba, si hubiera una sola posibilidad de elegir entre Alpha y Alpha', todavía podría resultar razonable elegir Alpha si se pudiera lograr una redistri-

${ }^{55}$ Véase, en general, Kaplow y Shavell (2002). 
bución equitativa de la riqueza mediante un impuesto inferior a diez dólares.

En general, no habrá necesidad de hacer una redistribución sistemática de los costos y beneficios de una regulación — debido a que una distribución no igualitaria tendería a quedar anulada-, a no ser que haya algún sesgo sistemático, de modo que algunos grupos estén siempre obligados a pagar por los beneficios que obtienen otros. En esos casos, también podría ocurrir que una mirada más general a la desigualdad, incluyendo las desigualdades ocasionadas por opciones de política y también la desigualdad que surge del mercado, conduzca a una política redistributiva más eficiente, debido a que se puede realizar de manera integral y no a través de medidas correctivas graduales a nivel de políticas individuales. La redistribución holística se puede hacer mediante un sistema ya sea de impuestos o transferencias o, cuando sea apropiado, mediante regulaciones dirigidas a producir beneficios distributivos positivos, aun cuando incluso no sean óptimas desde una perspectiva puramente económica.

Al comprender, considerándolo bien, que un enfoque holístico de redistribución puede resultar óptimo — con políticas ambientales y de salud pública diseñadas para maximizar la riqueza y una política de impuesto-y-transferencia, o incluso con políticas ambientales y de salud pública ineficientes pero que están dirigidas a corregir desigualdades en la distribución del bienestar-, debería no obstante tomarse en cuenta la distribución de los costos y beneficios a nivel de las políticas individuales. En particular en aquellos casos en que la redistribución progresiva de los costos o beneficios se puede lograr mediante cambios menores en las políticas, con costos más bajos en términos de eficiencia que redistribuir mediante un sistema de impuestos y transferencias, naturalmente se justificaría introducir esos cambios.

También podría suceder que, aun cuando la redistribución a través del sistema de impuestos y transferencias sea eficiente, resulte difícil en términos políticos por una variedad de razones. Si ése fuera el caso, el sistema regulatorio sería la segunda mejor opción para corregir las desigualdades distributivas. En este escenario sería más eficiente usar un enfoque holístico, que considera a todas las regulaciones de manera sistemática para determinar las distribuciones, y que corrige algunas políticas cuando las metas de distribución se pueden lograr a un menor costo. 
Solamente en los casos donde un sistema de impuestos y transferencias esté completamente fuera de lugar, y que también resulte difícil modificar las regulaciones mediante un enfoque holístico, sería más eficiente, para lograr las metas de equidad, incluir disposiciones distributivas en el análisis costo-beneficio. En realidad, éste podría ser el caso para muchos países. En los Estados Unidos, por ejemplo, la política de impuestos y transferencias es políticamente impopular y corregir mediante cambios en las regulaciones es extremadamente difícil y requiere mucho tiempo. En estas circunstancias, se justificaría introducir correcciones distributivas a nivel de cada política.

Hay una variedad de herramientas que se pueden usar para incorporar explícitamente la distribución de costos y beneficios en la toma de decisiones regulatorias. El enfoque más popular es la ponderación de la equidad (equity weighting), donde los beneficios y los costos son tratados de manera diferente en función de la población afectada. Los sistemas de ponderación de la equidad se han usado en el Reino Unido y por el Banco Mundial ${ }^{56}$. La ponderación de la equidad también ha sido materia de importantes discusiones en la literatura económica ${ }^{57}$.

Con la ponderación de la equidad, los costos y los beneficios cuentan más para los más pobres que para las poblaciones más adineradas. Por ejemplo, con un simple esquema de ponderación en que los costos y beneficios para B son cuatro veces más importantes que para A, podemos apreciar que diferentes resultados de la política son preferibles.

Según estas ponderaciones de equidad, las políticas Alphá y Beta serían preferibles, si se les considerara de manera individual o colectiva. Alpha genera una pérdida neta de cuarenta dólares, mientras que Alpha' genera un beneficio neto de cuarenta y cinco dólares. Beta tiene un beneficio neto de ciento cuarenta dólares, en tanto Betá tiene un beneficio neto de sólo cuarenta y cinco dólares. Entre las cuatro combinaciones posibles, (Alpha/Beta), (Alpha/Beta'), (Alpha'/Beta), (Alpha'/Beta $)$, la tercera —(Alpha'/Beta) — tiene el retorno neto más alto.

${ }^{56}$ Véase H. M. Treasury: The Green Book. Appraisal and Evaluation in Central Government, 25, 91-96 (2003), y Dr‘eze (1998).

${ }^{57}$ Véase, por ejemplo, Johansson-Stenman (2005). 


\begin{tabular}{|c|c|c|c|c|}
\hline & \multicolumn{2}{|c|}{ A $(.2)$} & \multicolumn{2}{|c|}{ B (.8) } \\
\hline & $\begin{array}{c}\text { Costos } \\
\$\end{array}$ & $\begin{array}{c}\text { Beneficios } \\
\$\end{array}$ & $\begin{array}{c}\text { Costos } \\
\$\end{array}$ & $\begin{array}{c}\text { Beneficios } \\
\$\end{array}$ \\
\hline Alpha & 0 & 40 & 80 & 0 \\
\hline Alpha, & 11 & 20 & 44 & 80 \\
\hline Beta’ & 20 & 0 & 0 & 160 \\
\hline Beta? & 11 & 20 & 44 & 80 \\
\hline
\end{tabular}

No hay consenso sobre cuáles son las ponderaciones de equidad más apropiadas. Típicamente, las ponderaciones distributivas se basan en la función de bienestar social que está conformada por la utilidad individual agregada, donde las funciones de utilidad individual son cóncavas para el ingreso — cada unidad adicional de ingreso produce menos utilidad que la unidad anterior ${ }^{58}$. Mientras que la estructura fundamental de la utilidad marginal decreciente del ingreso es ampliamente aceptada, no hay consenso respecto a cuál es la forma real de las curvas - a qué tasa el ingreso produce menor utilidad marginal. Incluso si un régimen de ponderación de equidad tuviese una aceptación generalizada, no sería tarea fácil definir las ponderaciones que se deberían usar.

\section{Equidad intergeneracional y tasa de descuento}

Un problema persistente con respecto al análisis costo-beneficio dice relación con el mecanismo a usar para descontar los beneficios futuros. En general, los flujos de caja futuros tienen menos valor - considerados todos los factores- que los flujos de caja presentes, de modo que el análisis costo-beneficio, en el contexto del año fiscal, va a descontar flujos de fondos futuros a valores presentes con el fin de hacer comparaciones válidas entre costos presentes y beneficios futuros de un proyecto. La tasa de descuento en un contexto puramente fiscal se establece de acuerdo a una tasa de retorno libre de riesgos (normalmente se estima entre un 2 y 3 por ciento) y luego se ajusta

${ }^{58}$ Véase, por ejemplo, Johansson-Stenman (2005). 
hacia arriba para incluir una prima de riesgo si no hay seguridad sobre los pagos del proyecto ${ }^{59}$. La tasa de descuento es algo diferente en un ambiente regulatorio y representa la tasa a la que una sociedad está dispuesta a sustituir consumo presente por consumo futuro. Habitualmente se estima que está compuesta por la suma de dos elementos: uno de ellos es la "tasa pura de preferencias en el tiempo"; y el otro, un término que represente los efectos del crecimiento económico en la utilidad marginal del consumo ${ }^{60}$. Esta fórmula se expresa de la siguiente manera:

Tasa de descuento social $=r+\mu g$

Donde:

$r$ es la tasa pura de preferencia en el tiempo,

g es la tasa de crecimiento esperado de consumo per cápita, y

$\mu$ es la elasticidad negativa de la utilidad marginal del consumo.

Sin embargo, no está claro que sea apropiado aplicar lisa y llanamente una tasa de descuento en un contexto regulatorio. Como asunto preliminar, vale la pena distinguir dos contextos diferentes en que ocurren los beneficios regulatorios en el futuro: un contexto de un período prolongado de latencia, y un contexto de generaciones futuras $^{61}$. El contexto de un período prolongado de latencia describe situaciones donde existe un largo intervalo entre la exposición al riesgo y la materialización de dicho riesgo. El ejemplo paradigmático es la exposición a cancerígenos: pueden pasar años o incluso décadas entre el lapso en que la persona estuvo expuesta a un químico tóxico y el diagnóstico de la enfermedad.

${ }^{59}$ El modelo más influyente para combinar una tasa libre de riesgo y un premio por riesgo para estimar la tasa de retorno de la inversión (y, por lo tanto, la tasa de descuento) es el "modelo de valoración de activos de capital” (capital asset pricing model, CAPM), desarrollado por un grupo de economistas en los años sesenta, incluyendo a William Sharpe, Harry Markowitz y Merton Miller, quienes recibieron el Premio Nóbel de Economía por su contribución al desarrollo del modelo. En finanzas, el CAPM se usa para determinar una tasa de retorno teórica apropiada para un activo, si es que ese activo se debe agregar a un portafolio bien diversificado, dado que ese activo no tiene un riesgo que se pueda diversificar. Véase Grossman (1995).

${ }^{60}$ Véase Ramsey (1928), quien describe lo que se ha denominado Ecuación Ramsey.

${ }^{61}$ Véanse Revesz (1999) y Burton (1993). 
Distinto a la cuestión de latencia prolongada es el tema de las futuras generaciones. En el contexto de las futuras generaciones, se toman medidas hoy que van a reducir los riesgos en un futuro lejano. Esto significa que las personas que cargan hoy con los costos de la regulación son diferentes de las personas que recibirán los beneficios - hay una distinción temporal que implica que los dos grupos de personas serán muy distintos. El caso paradigmático de los beneficios para las generaciones futuras son las reducciones actuales de los gases que producen efecto invernadero. Debido al tiempo en que estos gases tienden a permanecer en la atmósfera, la disminución actual de las emisiones no va a generar una disminución sustancial de la concentración de emisiones en la atmósfera por muchos años.

El uso de una tasa pura de preferencias en el tiempo se justifica en un contexto de latencia prolongada. Para los peligros de latencia prolongada, la aplicación de una tasa de descuento es sólo una cuestión de respeto por las preferencias individuales. Si una persona prefiere disfrutar de los bienes ahora más que en el futuro, y prefiere aplazar los daños incluso si son inevitables, se debe respetar esa preferencia. Así como el análisis costo-beneficio no cuestiona las preferencias individuales de riesgos, no hay razón alguna para cuestionar las preferencias sobre la distribución de los riesgos a lo largo del tiempo.

Sin embargo, el contexto intergeneracional es diferente debido a que ahí la distribución del riesgo no se produce en dos épocas distintas para el mismo individuo, sino que la distribución es entre dos individuos diferentes. En este caso no se trata meramente de un asunto de respetar preferencias respecto a cuándo prefieren los individuos experimentar los costos y beneficios, sino que la asignación de mayores cargas o beneficios a diferentes grupos de personas constituye una decisión social. Son dos cuestiones distintas y se deben analizar de manera diferente. Esto es evidente con respecto a la tasa pura de preferencias en el tiempo. El término en la fórmula de descuento social que considera los retornos decrecientes del consumo se entiende y está bastante bien justificado. No es claro hasta qué punto se justifica una tasa pura de preferencias en el tiempo.

El debate sobre la tasa de descuento social ha adquirido especial importancia en el contexto del cambio climático. El Informe Stern (Stern Review), por ejemplo, que constituye la evaluación económica de mayor 
envergadura realizada por un organismo de gobierno sobre el cambio climático, usó una taza pura de preferencias en el tiempo cercana a cero para reflejar la noción moral de que las futuras generaciones deben ser tratadas con igual consideración ${ }^{62}$. Debido a que se usó una baja tasa de descuento, se encontró justificado establecer controles relativamente estrictos de los gases efecto-invernadero. Sin embargo, el Informe fue ampliamente criticado por economistas del mundo académico - muchos de los cuales apoyan límites obligatorios para las emisiones de gases efecto-invernadero- por usar una tasa muy baja de descuento social, que en su opinión habría distorsionado los resultados para favorecer un mayor gasto en el control del cambio climático ${ }^{63}$.

Si bien hay gran desacuerdo acerca del uso de una tasa pura de preferencias en el tiempo, el segundo término en la fórmula de la tasa de descuento social —que considera el efecto del crecimiento económico en la utilidad marginal del consumo - también podría plantear problemas en los países en desarrollo. Este término se puede desagregar en dos partes: la relación entre consumo total y la utilidad marginal del consumo, por un lado, y las predicciones sobre el crecimiento económico, por otro lado. Aunque está en discusión el término exacto para la elasticidad de la utilidad marginal del consumo, la intuición fundamental es ampliamente compartida y una utilidad marginal decreciente del consumo es un principio básico de la teoría económica. En general, por consiguiente, considerar el crecimiento proyectado del consumo no genera controversia.

Sin embargo, las tasas que se usan en los países desarrollados y en desarrollo para la proyección del crecimiento son probablemente muy distintas. Los países desarrollados han tenido crecimiento económico durante muchos años, y las economías más avanzadas por lo general tienen un nivel de crecimiento económico bajo, pero persistente. Debido a que están comenzando en un nivel más bajo, muchos

62 "Stern Review: The Economics of Climate Change" disponible en http:// www.hm-treasury.gov.uk/stern_review_report.htm part 1 at 31. Allí se señala que se adoptó un enfoque simple: "Si la generación futura estuviera presente, suponemos que demandaría la misma atención ética que la generación actual”.

${ }^{63}$ Véase, por ejemplo, Nordhaus (2007): "Los alarmantes hallazgos del Informe Stern sobre daños, así como su racionalidad económica, se basan en su modelo para establecer parámetros — una baja tasa de descuento en el tiempo y baja aversión a la desigualdad — que se traduce en tasas de ahorro y retornos reales que difieren ampliamente de la información actual de mercado". 
importantes países en desarrollo tienen altas tasas de crecimiento económico ${ }^{64}$.

Las tasas de crecimiento más altas en los países en desarrollo justifican tasas más altas de descuento. La consecuencia es que habrá menos regulaciones que beneficien a las generaciones futuras. En esencia, las tasas de descuento más altas reflejan la opinión de que la población del futuro va a ser más rica que la actual, y por lo tanto sería injusto redistribuir riqueza de la generación actual a la futura. Sólo en los casos en donde el valor de los beneficios futuros excede el valor de los costos en que se incurriría hoy se justificarían las regulaciones.

Pueden aparecer algunos problemas a raíz de las tasas diferenciales de descuento para los países en desarrollo. Primero, surge una vez más el problema de las comparaciones internacionales. Las acciones que se justifican en los países desarrollados para proteger a las generaciones futuras no se justificarían y podrían generar los problemas éticos y políticos discutidos anteriormente.

Quizás más primordial aun, usar tasas de crecimiento diferenciales para los problemas globales —el cambio climático es el más importante- podría llevar a resultados perversos. Las tasas de crecimiento más elevadas se originan, al menos en parte, en las etapas iniciales del desarrollo económico. Si bien algunos modelos de análisis costo-beneficio de cambio climático utilizan "ponderaciones de equidad" para explicar las tasas de consumo más bajas en los países pobres, muchos no lo hacen. El uso de tasas de descuento diferenciales, entonces, distorsionaría los resultados debido a que los retornos decrecientes del consumo se explicarían en un contexto - descontando los beneficios futuros-, pero no estarían considerados en otro contexto - la distribución actual de la riqueza. Esto crearía un sesgo en contra de aquellas políticas que beneficien a los países en desarrollo en el futuro: la equidad no se considera cuando hace aumentar el valor de los beneficios en los países en desarrollo, pero sí se toma en cuenta cuando causa una disminución del valor de los beneficios en esos mismos países.

Incluso en el ámbito interno de los países se debería cuidar este aspecto. Si la carga de las regulaciones actuales recae en los segmentos más adinerados de la población, pero los beneficios futuros se acumu-

64 Véase Central Intelligence Agency World Factbook, disponible en https:// www.cia.gov/library/publications/the-world-factbook/. 
lan en los segmentos menos adinerados de la población, entonces el supuesto de los retornos decrecientes del consumo no se sostiene necesariamente, y por cierto no se sostiene a la tasa de crecimiento general de la economía. El descuento tendría que considerar la incidencia de los costos y beneficios de la regulación no sólo en la dimensión del tiempo, sino que también debe tener en cuenta la distribución de riqueza dentro del país. En esencia, el descuento debería estar inserto en el proyecto más amplio de análisis de la distribución de costos y beneficios.

Existe otra posible trampa al usar una tasa de descuento elevada basada en la proyección de un alto nivel de crecimiento en el largo plazo. Una tasa de descuento muy elevada puede desincentivar las políticas de largo plazo y, en último término, puede traducirse en una disminución del crecimiento económico en el futuro dado que las generaciones actuales prefieren consumir antes que invertir en regulaciones. Si se aplica una tasa de descuento muy alta, las políticas que esa alta tasa de descuento está justificando deberían ser sometidas a un escrutinio adicional para verificar que no detengan el crecimiento económico que es la base primigenia de esa alta tasa. Si bien esto no significa que nunca se justifique el uso de una tasa de descuento elevada en base a una proyección de crecimiento del consumo, sí quiere decir que las tasas de descuento no se pueden incorporar sin ocasionar problemas al análisis costo-beneficio.

\section{Cómo adaptar el análisis costo-beneficio a los países en desarrollo}

El campo de la economía del desarrollo se centra en preguntas de la economía que conciernen al desarrollo y a los países en desarrollo, más que en cuestiones normativas que son materia de la economía del bienestar. La economía del desarrollo trata de responder preguntas sobre las consecuencias empíricas de las políticas, o de identificar políticas asociadas al crecimiento económico de largo plazo. Si esas políticas son "buenas" o no, es algo que deben determinar quienes formulan las políticas, y la economía del desarrollo no propone un conjunto de criterios últimos para determinar cuáles opciones se “deberían” elegir. 
Sin embargo, eso no quiere decir que la economía del desarrollo no tenga nada que ofrecer al análisis costo-beneficio. Las proposiciones de la economía del desarrollo pueden resultar valiosas para evaluar (normativamente) la sabiduría de una opción política concreta -el impacto de una política en el crecimiento puede tener importantes consecuencias para determinar sus beneficios netos.

\section{A. Efectos de la política ambiental en la acumulación de capital físico}

La acumulación de capital es una variable cuya influencia en el desarrollo está bien establecida ${ }^{65}$. Los países que no tienen acceso al capital cuentan con menos trabajadores productivos ${ }^{66}$, tienen menos oportunidades de participar en la economía global a través del comercio, y dependen en mayor grado de la producción agrícola y de las materias primas para crear riqueza - lo cual los somete a riesgos climáticos y a grandes fluctuaciones en los precios internacionales ${ }^{67}$. La acumulación de un amplio rango de activos que se consideran capital — desde fábricas hasta know-how tecnológico- está en el centro de la industrialización y el desarrollo.

La categoría más obvia de capital es la de carácter físico: maquinaria, fábricas, infraestructura de transporte y comunicaciones, capacidad de generación de energía e infraestructura inmobiliaria que ponen a la economía moderna en movimiento. El capital físico proporciona los cimientos para maximizar la productividad de los trabajadores y para aumentar la capacidad total de producción de bienes y servicios.

La regulación ambiental puede tener una variedad de impactos negativos y positivos en el capital físico. En el campo de la economía del medio ambiente, recientemente ha suscitado gran interés el concepto de los "servicios de los ecosistemas". La idea básica de los servicios de los ecosistemas es que se puede considerar a la propia naturaleza como una forma de capital físico que provee importantes servicios a la

${ }^{65}$ Urata (2002); Cao (1997); Seita y Tamura (1994).

${ }^{66}$ Véase Urata (2002).

${ }^{67}$ Eubanks II (2009): "En respuesta a la caída de los precios mundiales del algodón, por ejemplo, se estima que se suicidaron unos 40 mil campesinos productores de algodón en la India entre 1996 y 2005, y otros miles vendieron uno de sus riñones en el mercado negro por unos $\$ 800 ”$. 
comunidad. Ejemplos clásicos de los servicios de los ecosistemas incluirían la filtración del agua: los bosques protegidos o los humedales en una zona de cuencas mejoran la calidad del agua porque filtran la recarga de aguas-lluvia. Los programas de preservación que permiten evitar la construcción de costosos proyectos para filtrar el agua es un aspecto crucial del programa de manejo del agua en la ciudad de Nueva York, por ejemplo. En este caso, manejar un recurso natural existente puede evitar la necesidad de dedicar recursos sociales para construir nuevo capital físico — recursos que se pueden destinar a mejores usos en la economía.

Los países en desarrollo tienen una ventaja especial para proteger los servicios de los ecosistemas. Muchas economías avanzadas ya han transformado el capital natural para utilizarlo en la construcción de infraestructura — talar bosques para desarrollos inmobiliarios; rellenar los humedales; construir embalses en los ríos. Muchas de estas decisiones son irreversibles o muy costosas de revertir. Sin embargo, muchos países en desarrollo no se han encerrado en opciones específicas respecto a sus recursos naturales — hay allí importantes reservas de capital natural sin explotar. Tomar decisiones sabias respecto de estos recursos, incluyendo la de mantener la opción de apoyarse en los servicios de los ecosistemas en el futuro, es un activo clave que no se debe subestimar cuando los recursos naturales del mundo son cada vez más escasos.

Hay muchas otras formas en que la regulación del medio ambiente puede impactar el capital físico aparte de proteger de modo directo los servicios de los ecosistemas. La influencia en la inversión extranjera directa es, sin duda, una consideración importante. Una queja común entre los líderes sindicales de los países desarrollados es que otros gobiernos, al mantener bajos niveles de regulación ambiental, atraen "injustamente" capitales a sus costas. Desde luego, cuando los efectos de la menor regulación son locales, esto simplemente representa una compensación —una disposición a sufrir costos ambientales adicionales con el fin de generar beneficios económicos. La situación es más complicada, por supuesto, cuando hay externalidades y los efectos de las opciones de los gobiernos locales se esparcen a otras regiones. En esos casos, los acuerdos ambientales y la cooperación son necesarios para evitar que ineficientemente se produzcan elevados niveles de contaminación. 
Si bien la retórica estándar de las compañías que se trasladan por el mundo en busca de los niveles más bajos de regulación tiene amplia aceptación, los efectos de la regulación ambiental en la inversión extranjera directa (FDI, por sus siglas en inglés) son complejos y debatidos $^{68}$. Hay muchos factores confusos que hacen que el estudio de la relación entre la FDI y la regulación ambiental sea difícil, incluyendo las variaciones regionales y numerosas variables que podrían ser omitidas — tales como estabilidad, ubicación, abundancia de recursos naturales, corrupción local y conexión local. Las variables de "tercer país”, cuando factores externos al país inversionista o al país que recibe la inversión afectan la inversión, presentan un problema particularmente complejo ${ }^{69}$. Algunos sostienen que la causalidad corre en la otra dirección, desde la inversión extranjera directa hacia estándares ambientales más bajos ${ }^{70}$. Si bien no está claro el conocimiento económico al respecto, los países deberían reconocer explícitamente cuáles son los riesgos para la inversión extranjera directa que imponen los estándares ambientales altos ${ }^{71}$.

Asimismo, la regulación ambiental también puede tener efectos positivos en ciertas áreas de la inversión extranjera directa. El ejemplo más obvio es la industria del turismo. La inversión en la conservación puede traer dividendos en dólares provenientes de los turistas que visitan los parques nacionales; la inversión en controlar el agua limpia protege lagos, ríos y áreas costeras que generan actividad económica y que atraen inversión extranjera en hoteles, centros vacacionales y otras industrias locales asociadas. Dado el gran tamaño de la industria turística global ${ }^{72}$, y el grado en que algunos países en desarrollo

${ }^{68}$ Véase, en general, Fullerton (2006).

${ }^{69}$ Véase Kukenova y Monteiro (2008).

${ }^{70}$ Cole et al. (2004).

${ }^{71}$ Aclarar el grado de riesgo que representan las regulaciones ambientales estrictas para la inversión extranjera directa también puede ayudar a aliviar los temores asociados a nuevas políticas ambientales — si no se reconocen los efectos sobre la inversión o si no se investigan adecuadamente, entonces es más fácil explotar esos miedos con el fin de detener un avance fundamental, incluso si los temores son infundados o desproporcionados en relación con el riesgo real.

${ }^{72}$ Según el World Travel and Tourism Council, se espera un crecimiento del valor de los viajes y del turismo desde \$5.474 billones en 2009 hasta \$10.478 billones hacia 2019. Véase World Travel and Tourism Council: Tourism Impact Data and Forecasts, disponible en http://www.wttc.org/eng/Tourism_Research/Tourism_Economic_Research/. De acuerdo con la Organización Mundial de Turismo de las Naciones Unidas, el turismo internacional representaba en 2003 aproximadamente 6\% de las exportaciones de bienes y servicios en el mundo. Véase United Nations World Tourism Organization: "Tourism and the World Economy”, en http://unwto.org/facts/eng/economy.htm. 
dependen del turismo para generar inversión ${ }^{73}$, es evidente el potencial que tiene la protección ambiental para generar inversión en infraestructura turística.

Que las protecciones ambientales incentiven o desincentiven la inversión extranjera directa es algo relacionado con el contexto específico. No siempre va a darse el caso de que la regulación ambiental aleje a los inversionistas extranjeros, pero tampoco es probable que las empresas, al decidir sobre un lugar, ignoren del todo los costos que implica cumplir con la regulación. Para tomar decisiones racionales y bien pensadas en materia de política ambiental, examinar su impacto en la inversión extranjera directa — con sus efectos asociados sobre el desarrollo- es importante.

La regulación ambiental también puede incidir en la tasa de innovación tecnológica y en la adopción de nuevas tecnologías —estimulando la inversión en estas áreas. El papel de la tecnología en el crecimiento está bien asentado. A medida que se amplía el uso de la tecnología, aumenta la productividad de los trabajadores. Las ganancias en productividad de los trabajadores están en la base del crecimiento económico —si bien las instituciones son importantes, y el comercio y los mercados robustos crean beneficios económicos, es la habilidad con que se usa la tecnología para aumentar la productividad de los trabajadores lo que explica que el consumo haya tenido un alza enorme en muchas partes alrededor del mundo en los últimos siglos ${ }^{74}$.

Algunos economistas han planteado que la regulación ambiental puede aumentar la productividad directamente. La hipótesis de Porter sostiene que "la regulación ambiental más estricta (siempre y cuando sea eficiente) puede llevar a situaciones donde todos ganan (win-win situations), donde tanto el bienestar social como los beneficios netos privados de las firmas que operan bajo esa regulación pueden aumen$\operatorname{tar}^{75}$ ". Esto ocurriría porque las empresas no saben que tienen acceso a una variedad de innovaciones productivas que aumentan la productividad, por lo que la regulación ambiental forzaría a las empresas a

${ }^{73}$ Véase, por ejemplo, CIA World Factbook, Barbados, donde se señala que tres cuartos del PGB y un 80 por ciento de las exportaciones se deben a servicios relacionados con el turismo y otras industrias. Disponible en https://www.cia.gov/library/publications/the-world-factbook/geos/bb.html.

${ }^{74}$ Véase, en general, Maddison (2001).

${ }^{75}$ Wagner (2003). 
invertir en capacidad intelectual para estudiar detenidamente el proceso de producción y considerar nuevas tecnologías, incitándolas a aprovechar las oportunidades de innovación que anteriormente, en la situación de status quo ante, habían ignorado. Debido a que propone una irracionalidad a gran escala entre las empresas - bajo condiciones en que la competencia debería eliminar a las empresas menos eficientes-, la hipótesis de Porter es controvertida ${ }^{76}$.

Aun si la hipótesis de Porter no fuese válida, la adopción generalizada de tecnologías ambientales puede tener efectos indirectos positivos en otras áreas donde la tecnología aumenta la productividad. La inversión en tecnología para aumentar la productividad puede permitir ("piggy-back") que las inversiones mejoren su desempeño en términos ambientales —una regulación que exija estándares más altos para las calderas de la calefacción mediante el reemplazo de las calderas a petróleo por calderas a gas, puede ser una oportunidad para mejorar la calidad del medio ambiente, pero también para mejorar la eficiencia y generar ahorros netos para las empresas, por ejemplo. A medida que la sociedad responde a los controles de las emisiones de gases efecto invernadero, el replanteamiento de los diseños y procesos de producción gatillará inversiones en una amplia gama de áreas, algunas de las cuales, finalmente, estarán muy poco relacionadas con la intervención original del gobierno.

La relación entre regulación del medio ambiente y cambio tecnológico está bien establecida. El cambio tecnológico en respuesta a la regulación del medio ambiente ha sido documentado en muchos contextos, en los avances realizados para cumplir con el Protocolo de Montreal referente a las Sustancias que Dañan la Capa de Ozono ${ }^{77}$, en los cambios en los procesos de producción de los generadores de energía para reducir costos del Programa de Lluvia Ácida de los Estados Unidos $^{78}$, y en los recientes desarrollos tecnológicos para salvar la ampolleta de luz incandescente ante las inminentes regulaciones en pos de la eficiencia energética ${ }^{79}$. Esta innovación no sólo brota de la inver-

${ }^{76}$ Ibídem.

77 Victor (1999): "El Protocolo de Montreal, por ejemplo, se ha fortalecido con el tiempo, en parte porque la innovación tecnológica ha puesto a disposición del mercado sustancias benignas para sustituir las sustancias destructoras del ozono".

${ }^{78}$ Véase Ellerman et al. (2000).

${ }^{79}$ Véase el artículo de Leora Broydo Vestel: "Incandescent Bulbs Return to the Cutting Edge”, N. Y. Times, julio 5, 2009. 
sión realizada en investigación y desarrollo, sino que aumenta, en definitiva, el stock de capital físico de que dispone la sociedad para alimentar el crecimiento económico.

En el caso de la adopción de tecnologías, si bien muchos países en desarrollo están retrasados respecto de las economías avanzadas en el acceso a la tecnología, también tienen ciertas ventajas por cuanto no están encasillados en opciones específicas de tecnología basadas en decisiones pasadas. Por ejemplo, la infraestructura de transporte de Europa y de los Estados Unidos está muy “atada”, y al menos en los Estados Unidos depende fuertemente de los autos particulares que funcionan con bencina. En cambio, si bien la mayoría de los países en desarrollo han hecho alguna inversión en la construcción de una infraestructura de transporte similar, no tienen el mismo grado de compromiso, lo que les deja espacio para adoptar otro sistema a medida que surgen nuevas tecnologías.

Se da una situación parecida en la industria privada: los cambios en la producción son mucho más fáciles de implementar al inicio, cuando se está diseñando una planta, en vez de tener que modernizar después las instalaciones existentes para cumplir con la regulación ambiental. Debido a este mayor grado de flexibilidad, es sumamente importante que los países en desarrollo tomen en cuenta el potencial que tienen la innovación tecnológica y el cambio para reducir los costos de las medidas de protección ambiental.

\section{B. Regulación del medio ambiente y capital humano}

El capital humano —el cúmulo de experiencias y conocimientos de la fuerza de trabajo de los países— también está claramente relacionado con el desarrollo. Los nuevos campos de la teoría del desarrollo se han centrado, en particular, en cómo contribuyen los conocimientos, la educación y el know-how tecnológico al desarrollo ${ }^{80}$.

Es sabido que la inversión en educación genera ganancias en productividad y en el crecimiento económico ${ }^{81}$. Esto es especialmente

\footnotetext{
${ }^{80}$ Romer (1990).

${ }^{81}$ Gardner (1989); Baldacci et al. (2005): "un país con un nivel de alfabetización sobre el promedio de la muestra [...] experimenta un aumento sobre el promedio del crecimiento anual per cápita del PGB”.
} 
cierto a medida que los países incorporan tecnología y aumentan la productividad de los trabajadores. Los economistas han demostrado por generaciones que "en la medida en que los cambios en productividad son el resultado del cambio tecnológico, la mano de obra calificada adquiere mayor importancia y la necesidad de desarrollar capital humano se convierte en un factor crucial para el crecimiento continuo. Una fuerza de trabajo educada se adapta mejor a las innovaciones en el trabajo $^{82}$.

No obstante, también es bien sabido que "el mercado subinvierte en capital humano" 83 . Muchas de las inversiones necesarias para aumentar el capital humano se logran mediante subsidios estatales -el dinero gastado en construcción de colegios y en educación pública. Un mercado de capitales que funcione bien, donde la oferta de capital sea óptima para la inversión en capital humano, es casi imposible de imaginar: los niños tendrían que pedir préstamos para financiar su educación. Claramente habrá limitaciones cognitivas que interferirán con el adecuado funcionamiento del mercado. Si bien el capital privado puede tener un papel importante en la acumulación de capital humano - como en los Estados Unidos, donde los estudiantes se endeudan en importantes sumas para pagar sus estudios universitarios y de postgrado-, es casi seguro que se necesitarán subsidios estatales para lograr una inversión óptima.

La acumulación de capital humano no implica sólo educación formal. Aprender haciendo, capacitación en el trabajo, la difusión de la tecnología y del know how por medio de rotar a los trabajadores, son todas alternativas que funcionan, junto con el sistema de educación formal, para aumentar la capacidad de los trabajadores. Un ambiente de trabajo donde predomina la tecnología se retroalimenta a sí mismo: los trabajadores adquieren conocimiento técnico que pueden fácilmente incorporar en sus oficios; los gerentes pueden adoptar procesos de producción en nuevas áreas y los innovadores tienen amplias oportunidades para nutrirse de los otros. Todos contribuyen conjuntamente a disminuir los costos de puesta en marcha de nuevas tecnologías, lo cual repercute en un ciclo virtuoso de mayor productividad laboral.

\footnotetext{
${ }^{82}$ Compárese Blakemore y Herrendorf (2009) con Nelson y Phelps (1966), que plantean este argumento.

83 Véase Basu (1997).
} 
Hay una gran variedad de vías mediante las cuales la regulación ambiental puede incidir en el capital humano. Tal como se mencionó anteriormente, la regulación ambiental puede ayudar a difundir la tecnología —aumentando el capital humano de los trabajadores expuestos a la tecnología. Los gerentes e ingenieros se ven obligados a estudiar detalladamente los procesos de producción, lo que los expone a nuevos desarrollos tecnológicos. La experiencia adquirida a raíz de la implementación de tecnología para controlar el medio ambiente puede ser transferida fácilmente a otras situaciones donde la incorporación de tecnología más sofisticada puede mejorar la productividad de los trabajadores. La regulación ambiental, por consiguiente, puede actuar como un estímulo periódico para que las empresas y los trabajadores mejoren sus tecnologías - y por ende sus habilidades-, lo cual, en conjunto con la oportunidad para usar esas habilidades en un ambiente de trabajo más amplio, facilita la creación de un ciclo virtuoso para el desarrollo de capital humano.

La regulación del medio ambiente también puede contribuir en forma más directa a la acumulación de capital humano. La contaminación ambiental tiene un amplio rango de efectos dañinos para la salud, aumenta los riesgos de largo plazo y agrava las condiciones que interfieren con la educación y la productividad de los trabajadores. Las neurotoxinas y las toxinas que alteran la endocrina tienen especial importancia porque pueden tener efectos de largo alcance en la capacidad intelectual. Hay numerosos ejemplos bien conocidos de contaminantes ambientales, entre ellos, el plomo y el mercurio, que pueden ser lesivos para el desarrollo neurológico. En especial las mujeres embarazadas no deben exponerse a las neurotoxinas. No puede haber una inversión más acertada en capital humano que la de asegurar que las futuras generaciones no queden expuestas a contaminantes que reducen de manera permanente la capacidad de aprender.

La regulación ambiental también puede contribuir a generar capital humano ayudando a las empresas a atraer y a retener a los trabajadores más capacitados. La calidad del medio ambiente y las instalaciones son atributos claves en cualquier lugar de negocios o trabajo, y si una firma está localizada en un lugar con mala calidad ambiental, tendrá que pagar algo más para retener a una fuerza laboral de la misma calidad que la de una empresa situada en un lugar donde hay buenas instalaciones y calidad ambiental. Al proporcionar un ambiente limpio, los gobiernos subsi- 
dian el esfuerzo por contratar trabajadores con habilidades que tienen alta demanda. La presencia de trabajadores altamente calificados también incide en la productividad de otros trabajadores - para las tareas que deben realizarse en un determinado lugar, la capacidad de atraer empleados competentes es vital para maximizar el potencial de todos los trabajadores. Una forma palmaria de este fenómeno es la que se conoce como “Teoría O-Ring”84, según la cual si algún trabajador no realiza su trabajo adecuadamente, se generan disminuciones de productividad a gran escala en toda la compañía. Ciertos cargos clave -incluyendo las gerencias, ingeniería, o ventas y publicidad - pueden ser considerados como los componentes "o-ring” de la productividad de la empresa. La calidad del medio ambiente y las instalaciones pueden incidir en que sea más barato para las empresas contratar a este tipo de personal, con beneficios de productividad que pueden extenderse a todos los trabajadores de una compañía.

Los efectos distributivos de la política ambiental también deben considerarse en el contexto de la acumulación de capital humano. Incluso en sistemas donde la educación pública es generalizada, los actores privados están llamados a realizar una importante contribución a la acumulación de capital humano: dándoles a los niños una adecuada nutrición y atención; pagándoles los materiales escolares; impidiendo que los niños adquieran compromisos laborales durante la adolescencia; pagando los gastos universitarios y de postgrado (incluyendo alojamiento y alimentación); garantizando los préstamos de los estudiantes - todas estas inversiones privadas vitales se suman y representan una cantidad importante del gasto social en acumulación de capital humano. Si embargo, estos gastos no los pueden realizar las familias que viven a nivel de subsistencia o similar, o con ingresos muy bajos. Para que sea posible invertir en educación, otras necesidades deben proveerse en niveles adecuados.

En la medida en que la regulación ambiental tenga consecuencias negativas en términos distributivos, en especial para los sectores de más bajos ingresos de la sociedad, como consecuencia disminuirá el gasto en acumulación de capital humano, socavando los esfuerzos sociales para promover el desarrollo. Es necesario identificar todo efecto distributivo pernicioso y, hasta donde sea posible, debe ser contra-

${ }^{84}$ Basu (1997), pp. 33-36. 
rrestado mediante políticas alternativas o programas de compensación. De lo contrario se corre el riesgo de obstruir una de las vías más conocidas para generar crecimiento económico de largo plazo.

\section{Trampas de la pobreza}

Además de identificar algunos de los requerimientos clave para el crecimiento, la economía del desarrollo analiza las condiciones que son perjudiciales para el crecimiento, en especial ciclos viciosos donde un conjunto de condiciones interactúan creando circuitos de retroalimentación negativa que obstaculizan el crecimiento económico. Evitar estas "trampas de la pobreza" es una meta importante de la economía del desarrollo.

Hay varias trampas de pobreza que son importantes para la regulación del medio ambiente y que un país en desarrollo debe considerarlas en el análisis costo-beneficio, al momento de anticipar los efectos de una nueva normativa. Si bien ninguna de estas consideraciones deberían guiar el análisis, no obstante se deben examinar detenidamente cuando se desarrollan políticas medioambientales.

Uno de los retos persistentes en numerosos países en desarrollo es hacer que los beneficios del crecimiento lleguen a toda la población. A medida que los países se industrializan, ingresan a la economía global a través del comercio e invierten en educación y en infraestructura pública, muchos de los efectos positivos del progreso llegan sólo a un pequeño porcentaje de la población que, por lo general, está concentrado en prósperas mini economías ubicadas en los centros urbanos ${ }^{85}$. A menudo no es posible lograr gran productividad en muchos sectores por falta de instituciones legales, incluyendo sólidos derechos de propiedad ${ }^{86}$. Aun cuando el PBI per cápita u otros indicadores de crecimiento económico aumentan, la vida de una parte importante de la población, en especial la

85 Según Blanchard (2005): "la política de modernización de China [...] ha acrecentado la disparidad económica entre una pequeña fracción de la elite urbana y los cientos de millones de campesinos que están muy alejados de la nueva riqueza del país”. Véanse los informes del International Bank for Reconstruction and Development: “World Development Report” (2008) y “Agriculture for Development (2007). En este último se advierte que la diferencia entre los ingresos rurales y urbanos es enorme y sigue aumentando en los países en desarrollo".

${ }^{86}$ Para una evaluación controvertida de la importancia de los derechos de propiedad en los países en desarrollo, véase De Soto (2000). 
de los segmentos más pobres o las familias que habitan afuera del radio urbano, tiende a quedar al margen de la nueva prosperidad. Los beneficios del crecimiento se concentran en pequeñas elites que viven en los centros urbanos (inner economy), mientras que numerosos trabajadores no calificados que viven fuera de los centros urbanos (outer economy) no participan de la nueva prosperidad.

Cuando la economía dual es un problema, ello debe tenerse en cuenta al momento de desarrollar políticas ambientales. Si algunas regulaciones crean barreras de entrada a la economía formal — por ejemplo, al establecer complicados sistemas contabilidad ${ }^{87}$ o someten a los pequeños empresarios a la acción arbitraria e inapelable de los burócratas ${ }^{88}$ - , podría exacerbarse el problema de la economía dual; en este caso se deberían preferir las alternativas de regulación que no generan este problema.

La política ambiental también puede ayudar a disminuir los problemas de una economía dual. Los programas de preservación pueden a veces tener consecuencias negativas para las comunidades rurales porque los grupos locales ven la protección ambiental como un despojo de recursos productivos, pero también se pueden diseñar de manera tal que incorporen a los grupos locales y ayuden a estimular el desarrollo económico local ${ }^{89}$. Por ejemplo, en lugar de la quema de tierras forestales para destinarlas (normalmente por un corto período ${ }^{90}$ ) al pastoreo, los individuos locales pueden trabajar en programas de preservación; o se puede subsidiar a las industrias locales que usan las tierras de los bosques de manera sustentable ${ }^{91}$. Al centrarse en cómo las políticas

${ }^{87}$ International Bank for Reconstruction and Development: "Can Africa Claim the 21st Century?” (2000): "En muchos países las regulaciones y las prácticas restrictivas, a menudo con el propósito de generar rentas para los funcionarios públicos y para grupos favorecidos, contraen la actividad empresarial y afectan a la agricultura y a la industria”. Burki y Perry (1997) señalan que regulaciones innecesarias, que implican un excesivo papeleo y costos administrativos, producen resultados económicos ineficientes.

${ }^{88}$ Nabli (2007) plantea que "Algunos estudios han descubierto que [...] emerge una burocracia honesta y eficiente como el componente [del gobierno] que tiene más vínculos fuertes con el desarrollo y el crecimiento económico”.

${ }^{89}$ Sobrevila (2008).

${ }^{90}$ Véase Pearce et al. (2002).

${ }^{91}$ Véase, por ejemplo, United Nations Foundation: UNDP Helping Coffee Growers Adjust To Economic Crisis (2002), disponible en http://www.unwire.org/unwire/ 20021115/30382_story.asp. Allí se señala que un programa de Naciones Unidas para el desarrollo en Guatemala proporciona crédito, capacitación y apoyo para el desarrollo de cultivos alternativos, y asistencia técnica a los campesinos con el propósito de disminuir la erosión y diversificar la economía local. 
ambientales afectan a los problemas de una economía dual, el análisis costo-beneficio puede ayudar a identificar las regulaciones que minimizan los efectos negativos para los más pobres de la sociedad, y contribuir a derribar las barreras entre los sectores más beneficiados de la economía y aquellos que no participan de dichos beneficios.

Otra trampa de pobreza bien conocida atañe a la estabilidad política y su relación con las fluctuaciones de la economía. Si una economía es propensa a tener fuertes ciclos de auge y decadencia, aunque tenga, en promedio, un crecimiento económico positivo, genera condiciones para que haya inestabilidad política; esta situación puede llegar a ser una amenaza para la inversión extranjera, drenar el capital humano y estimular la adopción de políticas que surgen de una motivación política y que tienen un impacto negativo en el crecimiento de largo plazo. Si una política puede ayudar a suavizar los vaivenes económicos, o si, en general, hace que un país tenga menos inestabilidad política, ello representa un claro beneficio que se debería tener en cuenta. Del mismo modo, si las políticas tienden a tener fuertes impactos cíclicos, o si socavan la estabilidad, ése es un costo que igualmente se debe considerar.

La política ambiental podría tener efectos que acrecienten o disminuyan el vigor de un ciclo de negocios. Por ejemplo, el gasto en inversiones ambientales de largo plazo se podría sincronizar para que estimule la economía en los períodos de bajo crecimiento —ésta fue la lógica con que se crearon muchas de las disposiciones de la Ley de Recuperación y Reinversión Norteamericana (American Recovery and Reinvestment Act) que aprobó el Congreso de los Estados Unidos a principios de 2009. China, en una ronda reciente de gastos para estimular la economía, también invirtió fuertemente en proyectos destinados a mejorar el medio ambiente $^{92}$. En épocas de auge se pueden recaudar impuestos que podrían servir para acumular reservas para eventualmente ser usadas en la protección del ambiente durante los años recesivos.

La regulación del medio ambiente también puede tener efectos cíclicos y contracíclicos. Es probable que medidas tales como limitaciones para el uso del suelo, impuestos ambientales y requisitos de contaminación tengan un efecto negativo en el crecimiento y es dable

\footnotetext{
${ }^{92}$ New York Times: "Stimulus Is Greenest in South Korea and China”, Sept. 24, 2009, disponible en http://www.nytimes.com/2009/09/25/business/global/25green.html. Allí se cita el Programa Medioambiental de las Naciones Unidas, señalándose que "China está entre las veinte economías más grandes del mundo en cuanto al porcentaje de estímulos económicos en dinero que invierte en proyectos para el medio ambiente”.
} 
esperar que tengan una creciente gravitación a medida que aumenta la tasa de crecimiento, lo cual va a proporcionar un mecanismo automático de desaceleración cuando se calienta la economía ${ }^{93}$. Al encausar el desarrollo económico de manera productiva, la regulación ambiental también puede hacer que los períodos de crecimiento se usen bien, en vez de construir en exceso y de explotar los recursos naturales en forma precipitada, lo cual aporta muy poco al stock de capital físico o humano. Cuando la tasa de crecimiento es baja o cercana a cero, es poco probable que regulaciones ambientales bien diseñadas frenen de manera significativa el crecimiento económico; las economías de bajo crecimiento, en lugar de buscar todas las posibles oportunidades de inversión, suelen verse asediadas por la incertidumbre y los excesos de stocks, o por capitales improductivos debido a malas inversiones. En estos casos las regulaciones se pueden estructurar de manera que proporcionen mayor seguridad al mercado y les den señales a los inversionistas de que hay potencial para emprendimientos rentables.

Naturalmente, la regulación ambiental también puede agravar los ciclos de negocios si durante los períodos de bajo crecimiento se implementan políticas muy exigentes, difíciles de tramitar o poco económicas, y durante los períodos de crecimiento se relajan los regímenes regulatorios. Un ejemplo de ello puede ser el caso de la regulación financiera en la que poderosos grupos de presión financieros logran reducir las regulaciones cuando los mercados están funcionando bien, pero si los mercados fallan, intervienen los encargados de formular políticas para controlar el problema, cuando los mercados ya se han corregido. La regulación ambiental podría seguir una trayectoria similar si se les da mayor libertad de acción a las industrias cuando están generando crecimiento, pero pierden poder político en los puntos bajos del ciclo de negocios y enfrentan mayor vigilancia de parte de los funcionarios públicos durante esos períodos. La meta debería ser tener niveles más estables de regulación a través de todo el ciclo de negocios $\mathrm{y}$, si es posible, usar la regulación para canalizar el crecimiento de la manera más productiva durante los ciclos de crecimiento y resolver la incertidumbre y estimular la inversión en los ciclos de baja.

${ }^{93}$ Goodhart et al. (1998) señalan que "Al Banco Central le corresponde establecer medidas restrictivas cuando empieza la fiesta”. 


\section{Conclusión}

Uno de los problemas más complejos del análisis costo-beneficio, y del desarrollo en general, es decidir cómo cambiar consumo de corto plazo por inversión de largo plazo. Si los países invierten muy poco, se arriesgan a acortar el ciclo virtuoso de acumulación de capital que permite el aumento constante de la productividad de los trabajadores. Pero si hay demasiada inversión, se transforma en una amenaza para las coaliciones políticas que son necesarias para mantener la estabilidad — los países deben realizar un delicado acto de malabarismo para proteger los intereses de las futuras generaciones y mantener contentas a las generaciones presentes. Estos temas son especialmente acuciantes en los países en desarrollo, donde hay importantes demandas inmediatas de alimentos, vivienda, educación básica y salud pública.

El análisis costo-beneficio, con los ajustes adecuados para considerar las circunstancias de los países en desarrollo —es decir, la vasta mayoría de la población mundial-, puede ayudar a tomar estas decisiones. Si bien la técnica nunca dejará de tener una connotación valórica o nunca será puramente técnica, puede ayudar a aclarar las opciones valóricas y contribuir a que los funcionarios que formulan las políticas tomen conciencia acerca de cuál es la manera más eficiente para lograr sus metas.

Si bien el análisis costo-beneficio se desarrolló en los países industrializados como una respuesta política a períodos breves de bajo crecimiento económico, es una técnica que tiene amplia aplicabilidad en todo el mundo. En su esencia, el análisis costo-beneficio es equivalente a un proceso racional de toma de decisiones —recaba la información disponible, identifica los objetivos, cuantifica la incertidumbre y elige la opción para cumplir esos objetivos que tenga menos consecuencias negativas. Para aquellos países que no tienen dinero para derrochar, pero que han priorizado la protección del medio ambiente como un componente importante del desarrollo sustentable, el análisis-costo beneficio puede ser la herramienta correcta en el momento preciso. 


\section{REFERENCIAS}

Adler, Matthew D. y Eric A. Posner (2006). New Foundations of Cost-Benefit Analysis. Harvard University Press.

Armantier, Olivier y Nicolas Treich (2003). "Social Willingness to Pay, Mortality Risks and Contingent Valuation”. Disponible en: http://www.sceco.umontreal.ca/ liste_personnel/armantier/papers/jru_final.pdf.

Baldacci, Emanuele, Clements Benedict, Cui Qiang y Gupta Sanjeev (2005). "What Does It Take to Really Help the Poor?” En Finance \& Development, Vol. 42.

Bank for Reconstruction and Development (2000): "Can Africa Claim the 21st Century?”.

(2007). “Agriculture for Development”. (2008). "World Development Report".

Basu, Kaushik (1997). Analytical Development Economics: The Less Developed Economy Revisited. MIT Press.

Blakemore, Arthur y Berthold Herrendorf (2009). "Economic Growth: The Importance of Education and Technological Development”. A Report from the Productivity and Prosperity Project, Jan. 2009.

Blanchard, Hal (2005). "Constitutional Revisionism in the PRC: Seeking Truth From Facts”. En Florida Journal of International Law, Vol. 17.

Boyle, Alan (2007). "Human Rights or Environmental Rights? A Reassessment”. En Fordham Environmental Law Review, Vol. 18.

Buchanan, James M. (1995). "Federalism as an Ideal Political Order and an Objective for Constitutional Reform”. En Publius, The Journal of Federalism, Vol. 25, $\mathrm{N}^{\circ} 2$ (primavera).

Burki, Shahid Javed y Guillermo E. Perry (1997). “The Long March: A Reform Agenda for Latin America and the Caribbean in the Next Decade”. International Bank for Reconstruction and Development.

Burton, Peter S. (1993). "Equity Considerations in Optimal Resource Harvesting”. En Journal of Environmental Economics and Management, Vol. 24, № 2.

Burtraw, Dallas, Richard Sweeney y Margaret A. Walls (2009). "The Incidence of U.S. Climate Policy: Alternative Uses of Revenues from a Cap-and-Trade Auction”. RFF Discussion Paper 09-17-REV, junio 2009.

Cao, Lan (1997). “Toward a New Sensibility for International Economic Development”. En Texas International Law Journal, Vol. 32.

Central Intelligence Agency (CIA). World Factbook. Disponible en https:// www.cia.gov/library/publications/the-world-factbook/.

Cole, Matthew A., Robert J. R. Elliott y Per G. Fredriksson (2004). "Endogenous Pollution Havens: Does FDI Influence Environmental Regulations?” University of Nottingham, Leverhulme Center for Research on Globalization and Economic Policy Research Paper 2004/20.

DeSoto, Hernando (2000). The Mystery of Capital: Why Capitalism Triumphs in the West and Fails Everywhere Else. Basic Books.

De Witt, Caroline (1993). “Comment The President's Council on Competitiveness”. En Administrative Law Journal of American University, Vol. 6.

Dr'eze, Jean (1998). "Distribution Matters in Cost-Benefit Analysis: Comment on K. A. Brekke”. En Journal of Public Economics, Vol. 70, № 3. 
Dworkin, Ronald (1981). "What is Equality? Part 1: Equality of Resources”. En Philosophy and Public Affairs, Vol. 10.

Ellerman, Denny, Paul L. Joskow, Juan Pablo Montero, Richard Schmalensee y Elizabeth M. Bailey (2000). Markets for Clean Air: The U.S. Acid Rain Program. Cambridge University Press.

Eubanks II, William S. (2009). “A Rotten System: Subsidizing Environmental Degradation and Poor Public Health With Our Nation's Tax Dollars”. En Stanford Environmental Law Journal, Vol. 28.

European Commission (2009). "Impact Assessment Guidelines”. 15 de enero. (2009): Communication from the Commission to the European Economic and Social Committee of the Regions, Third Strategic Review of Better Regulation in the European Union. 28 de enero.

Farrow, Scott, Eva Y. Wong, Julia Ghlke, William C. Griffith y Elaine M. Faustman (2004). “Assessing the Health Benefits of Air Pollution Reduction for Children”. En Environmental Health Perspectives, Vol. 112, No 2 (febrero).

Faux, Jeff, Carlos Salas y Robert E. Scott (2006). "Revisiting NAFTA: Still Not Working for North America’s Workers”. Briefing Paper No. 173, 2006, Economic Policy Institute.

Fullerton, Don (2006). The Economics of Pollution Havens. Edward Elgar Publishing.

Fullerton, Don and Karney, Dan (2009). "Does Environmental Protection Hurt LowIncome Families?”. Institute of Government \& Public Affair Policy Forum. Disponible en http://www.business.uiuc.edu/dfullert/IGPA-Policy-Forum0209.pdf.

Gardner, David P. (1989). "Education and The American Economy”. En Stanford Law \& Policy Review, Vol. 1.

Goodhart, Charles, Philipp Hartmann, David Llewellyn, Liliana Rojas-Suárez y Steven Weisbrod (1998). Financial Regulation, Why, How and Where Now? Routledge.

Grimm, Dieter (1995). “Does Europe Need a Constitution?”. En European Law Journal, Vol. $1, \mathrm{~N}^{\mathrm{o}} 3$.

Grossman, Peter Z. (1995). "The Market for Shares of Companies with Unlimited Liability: The Case of American Express”. En The Journal of Legal Studies, Vol. $24, \mathrm{~N}^{0} 1$.

Hahn, Robert (1998). "State And Federal Regulatory Reform: A Comparative Analysis 4”. Working Paper No 98-03, AEI-Brookings Joint Ctr.

Hammitt, James K. y Ying Zhou (2005). “The Economic Value of Air-Pollution-Related Health Risks in China: A Contingent Valuation Study”. En Environmental \& Resource Economics, Vol. 33, № 3.

H. M. Treasury (Reino Unido) (2003). The Green Book. Appraisal and Evaluation in Central Government. Reino Unido de Gran Bretaña e Irlanda del Norte.

Jensen, Derrick (2004). The Culture of Make Believe. Chelsea Green.

Johansson-Stenman, Olof (2005). "Distributional Weights in Cost-Benefit Analysis. Should We Forget About Them?”. En Land Economics, Vol. 81, No 3.

Jolly, Mette (2005). “A Demos for the European Union?”. En Politics, Vol. 25, No 1.

Kaplow, Louis y Steven Shavell (2002). "On The Superiority of Corrective Taxes to Quantity Regulation”. En American Law \& Economic Review, Vol. 4.

Kukenova, Madina y José-Antonio Monteiro (2008). "Does Lax Environmental Regulation Attract FDI When Account for Third Country Effects”. Disponible en http://papers.ssrn.com/sol3/papers.cfm?abstract_id=1292705. 
Maddison, Angus (2001). “The World Economy: A Millennial Perspective”. Organization for Economic Cooperation \& Development.

McCallion, Kenneth F. y H. Rajan Sharma (2000). "Environmental Justice Without Borders: The Need for an International Court of the Environment to Protect Fundamental Environmental Rights”. En George Washington Journal of International Law and Economics, Vol. 32.

Morgenstern, Richard (1997). "Economic Analyses at EPA: Assessing Regulatory Impact”. Resources for the Future.

Nabli, Mustapha K. (2007). "Breaking the Barriers to Higher Economic Growth: Better Governance and Deeper Reforms in The Middle East And North Africa”. International Bank for Reconstruction and Development.

Narula, Smita (2008). "Equal by Law, Unequal by Caste: The 'Untouchable' Condition in Critical Race Perspective”. En Wisconsin International Law Journal, Vol. 26.

Nelson, Richard R. y Edmund S. Phelps (1966). "Investment in Humans, Technological Diffusion, and Economic Growth”. En American Economic Review, Vol. 56, Nos $1 / 2$.

New York Times (2009): "Stimulus Is Greenest in South Korea and China”. Septiembre 24. Disponible en http://www.nytimes.com/2009/09/25/business/global/ 25green.html.

Nordhaus, William (2007). "Critical Assumptions in the Stern Review on Climate Change”. En Science, Vol. 317.

Pearce, David, Corin Pearce y Charles Palmer (2002). Valuing the Environment in Developing Countries: Case Studies. Edward Elgar.

Polaski, Sandra (2003). “Jobs, Wages, and Household Income”. En "Nafta's Promise and Reality: Lessons From Mexico for the Hemisphere”. Carnegie Endowment for International Peace. Disponible en http://www.carnegieendowment.org/files/ nafta1.pdf.

Rabkin, Jeremy (2000). “Is the EU Eroding the Sovereignty of Non-Member States?”. En Chicago Journal of International Law, Vol. 1.

Ramsey, Frank P. (1928). “A Mathematical Theory of Saving”. En The Economic Journal, Vol. 38, № 151.

Reed, Susan (1992). "Enemies of the Earth”. People Magazine (abril).

Revesz, Richard (1992). "Rehabilitating Interstate Competition: Rethinking the "Race to the Bottom' Rationale for Federal Environmental Regulation”. En New York University Law Review, Vol. 67.

- (1999). "Environmental Regulation, Cost-Benefit Analysis, and the Discounting of Human Lives”. En Columbia Law Review, Vol. 99.

Revesz, Richard y Michael Livermore (2008.). Retaking Rationality: How Cost Benefit Can Better Protect the Environment and Our Health. Oxford University Press.

Robinson, Lisa A. y James K. Hammitt (2009). "The Value of Reducing Air Pollution Risks in Sub-Saharan Africa”. Informe preparado para el Banco Mundial. Disponible en http://regulatory-analysis.com/robinson-hammitt-air-pollution-africa.pdf.

Romer, Paul M. (1990). “Endogenous Technological Change”. En Journal of Political Economy, Vol. 98, № S5.

Seita, Alex Y. y Jiro Tamura (1994). “The Historical Background of Japan’s Antimonopoly Law”. En University of Illinois Law Review, Vol. 1994. 
Sobrevila, Claudia (2008). “The Role of Indigenous Peoples in Biodiversity Conservation: The Natural but Often Forgotten Partners”. International Bank for Reconstruction and Development.

Soma, Bhattacharya, A. Alberini y M. L. Cropper (2007). "The Value of Mortality Risk Reductions in Delhi, India”. En Risk \& Uncertainty, Vol. 34, pp. 21.

Stern, Nicholas (2007). (Stern Review) The Economics of Climate Change. Cambridge University Press. Disponible en http://www.hm-treasury.gov.uk/stern_review_ report.htm part 1 at 31 .

United Nations Foundation (2002). UNDP Helping Coffee Growers Adjust To Economic Crisis". Disponible en http://www.unwire.org/unwire/20021115/30382_story.asp.

United Nations World Tourism Organization. "Tourism and the World Economy”. Disponible en http://unwto.org/facts/eng/economy.htm.

Urata, Shujiro (2002). "Competition Policy and Economic Development in East Asia”. En Washington University Global Studies Law Review, Vol. 1.

U.S. Environmental Protection Agency (EPA) (2000). Guidelines for Preparing Economic Analysis. Disponible en http://yosemite.epa.gov/ee/epa/eed.nsf/ webpages/Guidelines.html/\$file/Guidelines.pdf.

Vallette, Jim (2009). “Larry Summers' War Against the Earth”. Counter Punch, Disponible en http://www.globalpolicy.org/component/content/article/212/ 45462.html.

Vestel, Leora Broydo (2009). "Incandescent Bulbs Return to the Cutting Edge”. New York Times, julio 5.

Victor, David G. (1999). "Enforcing International Law: Implications For an Effective Global Warming Regime”. En Duke Environmental Law and Policy Forum, Vol. 10.

Viscusi, Kip (1978). "Labor Market Valuations of Life and Limb: Empirical Evidence and Policy Implications”. En Public Policy, Vol. 26.

Wagner, Marcus (2003). "The Porter Hypothesis Revisited: A Literature Review of Theoretical Models and Empirical Tests". Center for Sustainability Management Working Paper.

Weiler, J. H. H. (1995). "Does Europe Need a Constitution? Demos, Telos and the Maastricht Decision”. En European Law Journal, Vol. 1, № 3.

Wiener, Jonathan B. (2006). "Better Regulation in Europe”. En Current Legal Problems, Vol. 59.

Williamson, John (2004). “A Short History of the Washington Consensus”. Trabajo encargado por la Fundación CIDOB para la conferencia From the Washington Consensus Towards a New Global Governance, Barcelona, septiembre 24-25, 2004. Disponible en http://www.iie.com/publications/papers/williamson0904-2.pdf.

Wils, Wouter P. J. (1994). "Subsidiarity and EC Environmental Policy: Taking People’s Concern Seriously”. En Journal of Environmental Law, Vol. 6, Nº 1.

Woodward, Bob y David Broder (1992). “Quayle’s Quest: Curb Rules, Leave 'No Fingerprints”, Washington Post, enero 9, A1.

World Travel and Tourism Council. “Tourism Impact Data and Forecasts”. Disponible en http://www.wttc.org/eng/Tourism_Research/Tourism_Economic_Research/. 